Illinois State University

ISU ReD: Research and eData

Theses and Dissertations

$12-17-2013$

\title{
Tattoo Stigma and Job Discrimination
}

Phil Drazewski

Illinois State University, psdraze@ilstu.edu

Follow this and additional works at: https://ir.library.illinoisstate.edu/etd

Part of the Psychology Commons

\section{Recommended Citation}

Drazewski, Phil, "Tattoo Stigma and Job Discrimination" (2013). Theses and Dissertations. 148.

https://ir.library.illinoisstate.edu/etd/148

This Thesis is brought to you for free and open access by ISU ReD: Research and eData. It has been accepted for inclusion in Theses and Dissertations by an authorized administrator of ISU ReD: Research and eData. For more information, please contact ISUReD@ilstu.edu. 


\section{TATTOO STIGMA AND JOB DISCRIMINATION}

\section{Phil Drazewski}

71 Pages

May 2014

Recent research (Madera \& Hebl, 2011) has found that visible stigmas can lead to discrimination against stigmatized individuals in the form of lower job applicant ratings. Tattooed individuals may be one group that faces such discrimination. People with tattoos are perceived less positively than non-tattooed people (Martin \& Dula, 2010; Resenhoeft, Villa, \& Wiseman, 2008), which may be the result of a tattoo stigma. Pryor \& Reeder (2011) suggested that one hallmark of stigmas is that they evoke implicit negative attitudes. In a pilot study, participants implicitly and explicitly evaluated tattooed and non-tattooed individuals, and a tattoo stigma was supported. In the present study, tattooed (vs. non-tattooed) applicants were rated lower on overall effectiveness. However, unlike Madera \& Hebl (2011), the present study did not find memory to mediate the tattoo condition-effectiveness ratings relationship. Implicit tattoo-related attitudes, explicit tattoo-related attitudes, and participant gender were found to moderate the relationship between tattoo condition and candidate effectiveness ratings, and a number of additional participant demographic variables (i.e. age, number of tattoos, level of education) were found to be additional predictors of candidate effectiveness ratings. KEYWORDS: job discrimination, stigma, tattoo, implicit attitudes 
TATTOO STIGMA AND JOB DISCRIMINATION

PHIL DRAZEWSKI

A Thesis Submitted in Partial Fulfillment of the Requirements for the Degree of

MASTER OF SCIENCE

Department of Psychology

ILLINOIS STATE UNIVERSITY 
TATTOO STIGMA AND JOB DISCRIMINATION

PHIL DRAZEWSKI

COMMITTEE MEMBERS:

John Pryor, Chair

Eric Wesselmann 


\section{ACKNOWLEDGEMENTS}

I would like to thank my thesis committee members, Dr. John Pryor and Dr. Eric Wesselmann. Without their continued help, guidance, and patience, this thesis would never have come to fruition.

This thesis is dedicated to those who have felt stigmatized and/or experienced discrimination based on their physical appearance.

P.D. 


\title{
CONTENTS
}

\begin{abstract}
Page
ACKNOWLEDGEMENTS

CONTENTS

TABLES iv

FIGURES
\end{abstract}

CHAPTER

I. THE PROBLEM AND ITS BACKGROUND 1

II. REVIEW OF LITERATURE AND HYPOTHESES 5

Tattooing Today $\quad 5$

Attitudes toward Tattooed Individuals $\quad 6$

Tattoos in the Workplace $\quad 8$

Gender Differences in Tattoo Evaluation 10

Implicit and Explicit Attitudes toward People with Tattoos 11

$\begin{array}{ll}\text { III. } & 13\end{array}$

$\begin{array}{ll}\text { Participants } & 13\end{array}$

Procedure and Design 14

Mini Study 1: Evaluation of a Candidate Interview $\quad 15$

Mini Study 1: Measures 16

Mini Study 2: Evaluation of Abstract Art 17

Mini Study 2: Measures 17

Additional Survey Questions $\quad 18$

IV. ANALYSIS OF THE DATA 20

Attention Check, Manipulation Checks, and Outliers 20

$\begin{array}{ll}\text { Hypotheses } & 20\end{array}$ 
Explicit Attitudes $\quad 27$

Participant Age $\quad 28$

Number of Tattoos $\quad 29$

Participant Gender $\quad 31$

Ethnicity $\quad 32$

Level of Education $\quad 33$

V. SUMMARY AND CONCLUSIONS 35

VI. LIMITATIONS AND DIRECTIONS FOR FUTURE RESEARCH 39

Level of Concealability $\quad 39$

Animated vs. Static Interview Visuals $\quad 40$

Madera \& Hebl Techniques for Other Stigmas 41

Tattoo Research 41

$\begin{array}{ll}\text { REFERENCES } & 43\end{array}$

$\begin{array}{ll}\text { APPENDIX A: } & \text { Pilot Study }\end{array}$

APPENDIX B: $\quad$ MTURK Participant Recruitment Page $\quad 57$

APPENDIX C: $\quad$ Condition Photos Used in First Mini Study 58

APPENDIX D: $\quad$ Simulated Interview and Instructions 59

APPENDIX E: $\quad$ Memory Test and Instructions $\quad 62$

APPENDIX F: $\quad$ Effectiveness Evaluation Items and Instructions $\quad 65$

APPENDIX G: $\quad$ Affect Misattribution Procedure (AMP) Example Item $\quad 68$

APPENDIX H: $\quad$ Explicit Tattoo Attitude Scale $\quad 69$

APPENDIX I: $\quad$ Final Survey Questions and Instructions 70 


\section{TABLES}

Table

Page

1. Correlations, Means, and Standard Deviations of Mediation Model Variables

2. Correlations, Means, and Standard Deviations of Applicant Gender Moderation Analysis

3. Analysis of Applicant Gender as a Moderator of Tattoo Condition and Effectiveness Ratings

4. Correlations, Means, and Standard Deviations of Implicit Attitude Moderation Analysis

5. Analysis of Implicit Attitudes as a Moderator of Tattoo Condition and Effectiveness Ratings

6. Correlations, Means, and Standard Deviations of Explicit Attitude Moderation Analysis

7. Analysis of Explicit Attitudes as a Moderator of Tattoo Condition and Effectiveness Ratings

8. Correlations, Means, and Standard Deviations of Participant Age Moderation Analysis

9. Analysis of Participant Age as a Moderator of Tattoo Condition and Effectiveness Ratings

10. Correlations, Means, and Standard Deviations of Number of Tattoos Moderation Analysis

11. Analysis of Number of Tattoos as a Moderator of Tattoo Condition and Effectiveness Ratings 
12. Correlations, Means, and Standard Deviations of Participant Gender Moderation Analysis

13. Analysis of Participant Gender as a Moderator of Tattoo Condition and Effectiveness Ratings

14. Descriptive Statistics of Effectiveness Ratings at Each Ethnicity Level

15. Correlations, Means, and Standard Deviations of Level of Education Moderation Analysis

16. Analysis of Level of Education as a Moderator of Tattoo Condition and Effectiveness Ratings 


\section{FIGURES}

$\begin{array}{lll}\text { Figure } & \text { Page }\end{array}$

1. Proposed Mediation of Memory on the Relationship between Tattoo Condition and Applicant Effectiveness Ratings

2. Proposed Moderation of Applicant Gender on the Relationship between Tattoo Condition and Memory

3. Proposed Moderation of Implicit Attitudes on the Relationship between Tattoo Condition and Memory

4. Standardized Regression Coefficients for the Relationship between Tattoo Condition and Effectiveness Ratings as Mediated by Participant Recall

5. Variables Influencing Candidate Effectiveness Ratings 


\section{CHAPTER I}

\section{THE PROBLEM AND ITS BACKGROUND}

The job interview has proven to be one of the most widely utilized methods for employee selection (Campion, Palmer, \& Campion, 1997; Dipboye, 2005; Huffcutt \& Arthur, 1994). However, research continues to indicate that the job interview may only be a modest predictor of actual job performance (Hunter \& Hunter, 1984). This lack of validity may be attributed to interviewer bias associated with job applicant race, socioeconomic status, religion, dress, physical appearance, or even scent (Baron, 1983; Dipboye \& Colella, 2005; K. K. P. Johnson \& Roach-Higins, 1987). In such situations, applicants displaying undesirable traits face job discrimination regardless of how they respond to interview questions (Dipboye, 2005). The present study examined whether an increasingly popular physical trait - tattooing - is subject to a similar form of interviewer bias.

At its root, tattoo discrimination in interviews may be the result of perceived stigma. Goffman (1963) identified three types of stigma: (1) abominations of the body, (2) blemishes of individual character, and (3) tribal stigmas. Tattoos can be classified within each of these categories in that (1) they involve a deformation the body, (2) their presence is often regarded as a character blemish, and (3) they can signify a group/tribe membership. 
Goffman (1963), Jones \& French (1984), and Crocker et al. (1998) argued that bearers of perceived stigma - including job applicants displaying undesirable physical traits - can cause perceivers to feel a sense of uncertainty, discomfort, anxiety, or even danger during social interactions (Blascovich et al., 2001). Thus, though job interviewers may be motivated to appear non-prejudiced (Dunton \& Fazio, 1997), their self-reported attitudes may differ from their actual attitudes (Vanman et al., 1997).

These views are in line with more recent research indicating that reactions to stigmatized individuals involve two associated, yet distinct, processes: (1) a reflexive, unconscious process and (2) a deliberative, conscious process (Pryor, Reeder, \& Landau, 1999; Pryor, Reeder, Yeadon, \& Hesson-McInnis, 2004; Reeder \& Pryor, 2000).

Regarding the reflexive process, a number of negative reactions to abominations of the body (Bessenoff \& Sherman, 2000; Grandfield, Thomson, \& Turpin, 2005; Neumann, Husenbeck, \& Seibt, 2004), blemishes of individual character (Bassett \& Dabbs, 2005; Brener, von Hippel, \& Kippax, 2007; Jellison, McConnell, \& Gabriel, 2004), and tribal stigmas (Greenwald, McGee, \& Schwartz, 1998; Kawakami, Phills, Steele, \& Dovidio, 2007) have all been identified.

Such results have led Pryor \& Reeder (2011) to suggest that one hallmark of all stigmas is that they evoke implicit (unconscious) negative attitudes. Moreover, implicit attitude tests, such as the Implicit Association Test (IAT; Greenwald et al, 1998) and the Affect Misattribution Procedure (AMP; Payne et al., 2005), have given researchers ways to quantitatively assess and confirm stigmas at the implicit level. Such a technique 
(AMP) was used in my Pilot Study to test and confirm the existence of a tattoo stigma (see Attitudes toward Tattooed Individuals, Appendix).

Regarding the deliberative (as opposed to reflexive) process in Pryor et al.'s (2004)_dual-process model, research has shown that individuals also consciously use rules to determine whether it is socially appropriate to react negatively to a stigmatized person (Crandall \& Eshleman, 2003). In such cases, individuals have been shown to react less negatively to people whose stigmatizing conditions are beyond their control (e.g. blindness, ethnicity; Weiner, 1995; Pryor et al., 2004). In this vein, tattooed job applicants may consciously be judged more negatively by job interviewers who_fear stigma spread and/or feel threatened that they_may acquire stigma-by-association (Goldstein \& Johnson, 1997; Neuberg, Smith, Hoffman, \& Russell, 1994; Ostman \& Kjellin, 2002), which exists across many other stigmatizing conditions (Angermeyer, Schulze, Dietrich, 2003; Birenbaum, 1992; Corrigan, Watson, \& Miller, 2006; Hebl \& Mannix, 2003; Neuberg et al., 1994; Norvilitis, Scime \& Lee, 2002; Olson, Dunham, Dweck, Spelke, \& Banaji, 2008; Pryor, Reeder, and Monroe, 2012).

Feelings of threat that result from interactions with stigmatized persons are increasingly being examined, and visible stigmatizing conditions are being manipulated and compared in efforts to confirm a stigma-threat hypothesis. In 1994, Houston and Bull used facial birthmarks (port-wine stains) to manipulate stigma and found fewer people sat near an individual with a facial stigma than an individual without the stigma. In 2001, Blascovich and his colleagues found participants interacting with facially stigmatized 
partners exhibited a physical threat pattern (i.e. increased cardiovascular reactivity) and also generated fewer words than participants paired with non-stigmatized partners.

Recently, Madera and Hebl (2011) have built upon the research of Houston \& Bull (1994) and Blascovich et al. (2001) by bringing the study of stigma to the arena of the structured interview. In a study of facially stigmatized job applicants, Madera and Hebl found job discrimination to exist and be the result of perceived stigma negatively affecting attentional processes (Rinck \& Becker, 2006), which negatively affected working memory (Baddeley \& Hitch, 1974), and thus resulted in lower job applicant ratings. They also found participants evaluating facially stigmatized applicants depleted more regulatory resources (Muraven \& Baumeister, 2000) than participants evaluating non-facially stigmatized applicants.

Madera and Hebl's study was important in its ability to link perceived stigma to today's hiring practices. It also raised many questions for future research: Can other perceived stigmas lead to lower applicant ratings? What role may individual differences play in the evaluation of stigmatized individuals? The purpose of the current study was to evaluate whether job applicants displaying another potential stigma - tattoos - were subject to similar discrimination. 


\section{CHAPTER II \\ REVIEW OF LITERATURE AND HYPOTHESES}

\section{Tattooing Today}

In 2006, estimates on the number of tattooed individuals in the United States ranged from 10 or $20 \%$ (Kosut, 2006; Stirn et al., 2006) up to $24 \%$ of all adults and $40 \%$ of individuals between 21-31 years old (Laumann, 2006). A number of reasons have been given for why individuals choose to get a tattoo, including "expressing individuality, communicating rebellion, defining group membership, conveying spiritual meaning, or marking milestones such as life or death" (Christensen, 2000, p. 432). Tiggemann \& Hopkins (2011) found tattooing to represent a "bodily expression of uniqueness" and, interestingly, found one's number of tattoos to be significantly positively correlated with one's strength of identification with music (p. 245).

Tattooing in Psychology has been examined largely from a cultural perspective. In his books Criminal Anthropology (1895) and Savage Origins of Tattooing (1896), Cesare Lombroso laid out the foundations for literature examining the link between deviance and tattooing. Since then, researchers have noted the continuing associations between tattooed individuals and groups associate with deviance (e.g. prisoners, gang members; Atkinson, 2003). Recently, Burgess and Clark (2010) used such literature as a basis for examining whether the content of a tattoo makes a difference in how tattooed 
individuals are perceived. In their research, they found that individuals with traditional tattoos were rated less suitable for employment than those displaying contemporary tattoos.

Evolutionary psychologists are also increasingly examining why people get tattoos. One explanation, the "attractiveness increase hypothesis," states "people use body decorations to increase their own physical attractiveness or to hide some shortcomings in their appearance (e.g. low body symmetry)” (Koziel et al., 2010, p. 187). Other evolutionary psychologists have hypothesized that, because tattoos and piercings can present health risks, people who decide to decorate their bodies may be looking to express an "honest signal of genetic quality" (p. 187).

\section{Attitudes toward Tattooed Individuals}

For centuries, tattoos have invoked both positive and negative responses across varying societies. In some cases, tattoos have been seen as attractive despite being classified as signs of social deviance (Towler \& Schneider, 2005). Most studies, however, find that tattooed people are perceived less positively than non-tattooed people (Martin \& Dula, 2010; Resenhoeft, Villa, \& Wiseman, 2008), and people with tattoos are perceived as more "sensation seeking" and "having more previous sexual partners" than their nontattooed counterparts (Wohlrab et al., 2009, p. 3).

Possessing more visible and/or greater amounts of tattoos has also been shown to result in higher ratings of perceived negative/deviant behavior. DeMello (2000) noted that, when linked to behavior, tattoos can be seen as "a sign of a lack of discipline and self-control, of an inability to consider the future" (p. 140). In another investigation of 
tattoos and behavioral correlates, Haywood et al. (2012) found tattooing to be associated with risk-taking behaviors, including "smoking, greater numbers of lifetime sexual partners, cannabis use (women only) and ever having depression (men only)" (p. 51).

Even when theories linking tattoos with negative behavior are discredited, research shows that "individuals still tend to make stereotypical assumptions about others based on appearance" (Adams, 2012, p. 150).

I conducted a pilot study (see Appendix) to quantitatively evaluate attitudes toward tattooed (vs. non-tattooed) individuals as a precursor to the present study. In it, I set three goals for myself: (1) verify the existence of a tattoo stigma by assessing participants' implicit attitudes of tattooed (vs. non-tattooed) individuals, (2) explore the relationship between participants' implicit and explicit attitudes regarding tattooed (vs. non-tattooed) individuals, and (3) identify possible gender differences in the assessments of tattooed males and females.

In my hypotheses, I predicted that (1) participants would judge tattooed (vs. nontattooed) individuals as less attractive at both the implicit and explicit levels, (2) implicit and explicit attitudes regarding tattooed individuals would be highly correlated, and (3) in line with research indicating that tattooed women face a higher degree of discrimination than tattooed men (Hawkes, et al., 2004; Swami \& Furnham, 2007), tattooed females would encounter a larger drop in attractiveness ratings than tattooed males. All of my hypotheses were confirmed, and thus, the pilot study provided a springboard for studying the role of implicit attitudes regarding tattooed individuals in an applied setting. 
Such negative perceptions may have particularly profound impacts in applied settings (e.g. healthcare, the workplace) where the stakes are particularly high. Stuppy et al. (1998) found that physicians, registered nurses, and students studying healthcare, all had negative attitudes towards tattooed persons. Moreover, they found that physicians (MDs) and registered nurses (RNs) rated tattooed people less positively than student participants. They also noted that biases against tattooed individuals could lead to judgment and/or less sensitive care during their assessments.

Tattoos in the Workplace

Increasingly, tattooed individuals are being evaluated in the workplace, largely in the arenas of hiring practices and treatment. Attitudes towards tattooed individuals appear mixed, even among those in the field of business; for example, one survey of university business majors found that $65 \%$ of respondents "indicated that tattoos can be attractive" on both males and females (Totten et al., 2009, p. 88). In line with Houston and Bull's (1992) findings that "adults' reactions to stigmatized persons are a complex mixture of positive and negative responses," a mix of attitudes seems to also exist in the evaluation of tattooed individuals (p. 280).

Still, when examining hiring practices as a function of tattooing, attitudes appear largely negative. In one study, two in five adults reported that simply having a tattoo could justify being denied employment (Mann, 2005). In another, Dean (2011) found that, when participants were asked to rate tattooed white-collar workers (i.e. tax service providers), their tattoos were seen as "very inappropriate" and their service satisfaction ratings were significantly lower than blue-collared workers (p. 254). For these reasons, I 
predicted that tattoo stigma may be associated with job discrimination, and by applying the methods laid out by Madera and Hebl (2011), I set out to confirm such a relationship. On account of the findings of Mann (2005) and Dean (2011), I first hypothesized that:

Hypothesis 1: Tattooed (vs. non-tattooed) applicants will be rated lower on overall effectiveness.

Madera and Hebl examined how attentional processes mediated the relationship between the stigmatizing condition and memory. In doing so, they were able to confirm their hypotheses that (a) more visual attention would be given to the stigma location on a stigmatized (vs. non-stigmatized) applicant and (b) there would be less memory (i.e. recall) of what was said in the interview with a stigmatized (vs. non-stigmatized) applicant. Due to a lack of necessary equipment (i.e. eye-tracking technology), visual attention to tattoos was not examined in the current study; however, participant recall was assessed. In line with Madera and Hebl's findings, I hypothesized that:

Hypothesis 2: There will be less recall of what is said in interviews with tattooed (vs. non-tattooed) applicants.

Madera and Hebl also examined if, by attending more to a stigmatizing condition, an interviewer "might miss some important information from what the applicant said during the interview," which they thought might negatively influence the overall ratings of the applicant (p. 2). While finding (a) visual attention to mediate the relationship between stigma condition and memory recall and (b) memory to mediate the relationship between visual attention and the overall ratings of the applicant, they also found a direct 
effect of stigma on memory to be significant $(\beta=-.48, p<.05)$. Thus, though I could not assess the role visual attention plays in the discrimination process, I hypothesized that:

Hypothesis 3: Memory will mediate the relationship between tattoo condition and overall effectiveness ratings (Figure 1).

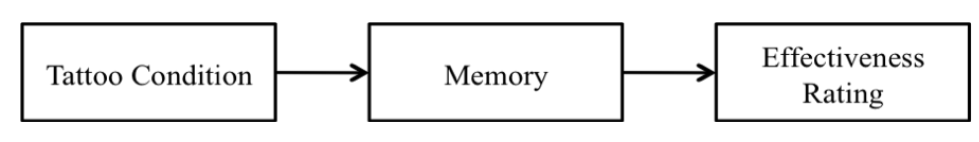

Figure 1. Proposed Mediation of Memory on the Relationship between Tattoo Condition and Applicant Effectiveness Ratings

\section{Gender Differences in Tattoo Evaluation}

Tattoos are not limited to certain types of individuals, yet certain groups face higher levels of stigmatization and/or discrimination than others. Time and time again, research has indicated that women, in particular, face a larger degree of stigmatization/discrimination than men (Hawkes, et al., 2004; Swami \& Furnham, 2007), though tattooing has been found to be equally common in both sexes (Laumann, 2006; Stieger et al., 2010). The pilot study found that gender did, in fact, moderate attitudes towards tattooed individuals, with tattooed women being evaluated more negatively than tattooed men (Appendix). In the present study, I examined if higher levels of discrimination against women would also be found in a job setting.

Tattooed career-oriented women have indicated that their tattoos make them feel "good, unique, and special" (Armstrong, 1991, p. 219). Still, studies have shown that visible tattoos on white-collar workers are deemed inappropriate while similar tattoos on blue-collar workers were viewed as appropriate (Dean, 2010). Therefore, tattooed women 
applying for a white-collar job may experience even more discrimination than tattooed women in a non-work setting. Thus, I hypothesized that:

Hypothesis 4: Applicant gender will moderate the mediation between tattoo condition and participant recall (i.e. memory), with participants remembering more information about tattooed females than tattooed males (Figure 2).

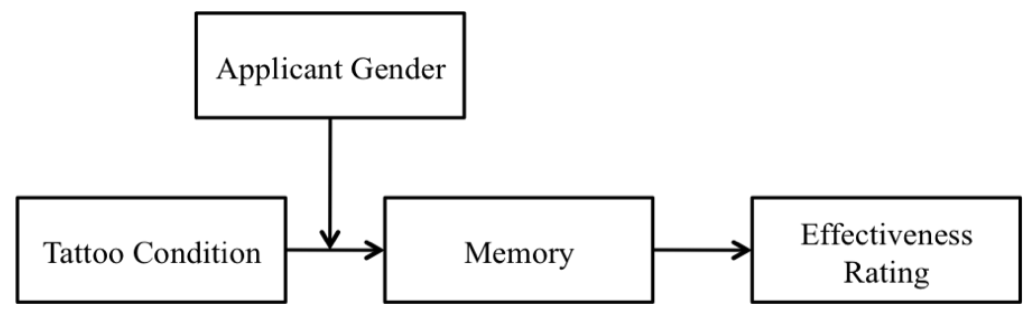

Figure 2. Proposed Moderation of Applicant Gender on the Relationship between Tattoo Condition and Memory

Implicit and Explicit Attitudes toward People with Tattoos

Though research pertaining to explicit attitudes towards tattooed individuals has given us insight into the processes involved in explicit evaluation, few (if any) studies have looked at the implicit processes involved in such assessments. Negative implicit attitudes are a hallmark of perceived stigmas (Pryor \& Reeder, 2011). In the pilot study (Appendix), a modified Affect Misattribution Procedure (AMP; Payne et al., 2005) revealed negative implicit attitudes towards tattooed individuals, supporting the existence of a tattoo stigma. In line with other research indicating that people attend more readily to negative stimuli than positive stimuli (Rinck \& Becker, 2006), attend to stigmas because 
they are novel (Langer et al., 1976), and discriminate against individuals displaying stigmatizing conditions (Madera and Hebl, 2011), I hypothesized that:

Hypothesis 5: Implicit tattoo-related attitudes will moderate participant recall with people who have more negative implicit attitudes about tattooed individuals recalling less than people who have more positive implicit attitudes (Figure 3).

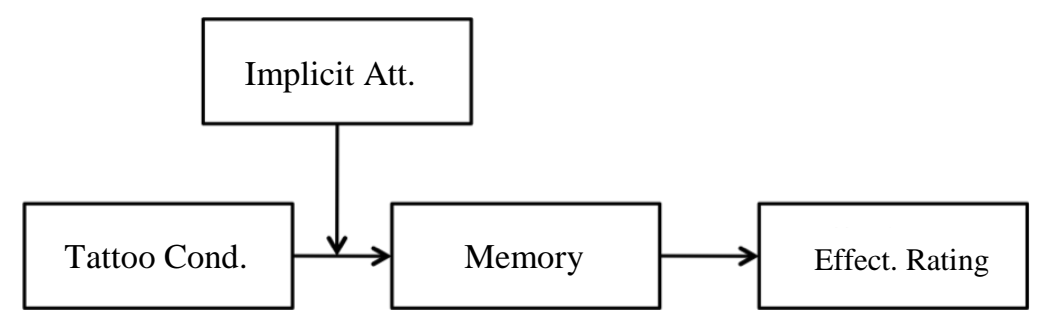

Figure 3. Proposed Moderation of Implicit Attitudes on the Relationship between Tattoo Condition and Memory

Finally, for exploratory reasons, I examined the role other individual differences play in moderating the relationship between tattoo condition and memory recall. To do so, I collected information regarding participants' explicit attitudes, own number of tattoos, gender, age, ethnicity, and level of education. No known research has confirmed that individual differences contribute to such moderation; thus, I explored whether participants' (a) explicit attitudes, (b) number of tattoos, (c) gender, (d) age, (e) ethnicity, and/or (f) level of education moderated the tattoo condition-participant recall relationship. 


\section{CHAPTER III}

\section{METHOD}

Participants

The desired sample size for the current study was 400 participants, with at least 100 participants viewing one of four job applicant tattoo-gender conditions: tattooed male, tattooed female, non-tattooed male, and non-tattooed female. Ns were determined using a power analysis, the medium effect size $\left(\eta^{2}=.03\right)$ found in Madera \& Hebl's (2011) manipulation of stigma, and additional literature, including Murphy \& Myors (2004) and Rossbach \& Wilson's (1992).

Participants were recruited through Mechanical Turk (MTURK) - an Amazon company that recruits "Workers" to complete various online tasks for "Requesters." Through MTURK, Requesters set up accounts to pay Workers for completing Human Intellectual Tasks (HITS). Over 100,000 users from over 100 countries complete tens of thousands of tasks daily on MTURK (Pontin, 2007).

I posted a brief description of the HIT on the MTURK website along with a description of the compensation. Participants were paid $\$ 0.15$ for completing a short study regarding social attitudes. Payment was made automatically by MTURK, transferring funds from the Requester's account to the Worker's account. Participation required individuals to be at least 18 years of age and speak English as their native 
language. I did not identify participants or access their contact information in any way.

Of the 884 participants that accessed the two-part study, 654 (74\%) fully completed at least the first interview-related mini study. Of this group, $542(83 \%)$ passed both the attention check and two manipulation checks (i.e. gender and tattoo condition) included within the first mini study. Of this group, 231 (43\%) identified as male, 306 $(57 \%)$ as female, and five participants $(<1 \%)$ did not identify their gender. Of this same group, 49 (9\%) identified as African American/Black, 429 (79\%) as Caucasian/White, 35 $(6 \%)$ as Asian American/Asian, and $29(5 \%)$ as another ethnicity. The average age of the participants was $32.1(S D=12.3)$, and of this group, $445(82 \%)$ participants completed the second, abstract art-related mini study (requiring Flash animation).

\section{Procedure and Design}

Through the MTurk HIT, participants were given a link that led them to an ISU server where they read an informed consent document (see Appendix). Once participants clicked a box acknowledging their agreement to participate, they were randomly assigned to one of four experimental conditions, representing the $2 \times 2$ study design (Tattoo vs. No Tattoo and Male Job Applicant vs. Female Job Applicant). The four conditions accessed Select Survey files on an ISU server.

On the first page of the Select Survey file (located on the ISU server), participants were informed that their participation in the study would consist of completing two mini studies. They were told that the first mini study involved their evaluation of an interview with an MBA graduate student applying for a job in marketing, and the second mini study 
involved their evaluation of a series of abstract art paintings. Below this paragraph, participants confirmed that they (1) were at least 18 years of age and (2) spoke English as their native language by clicking each respective option button. Lastly, they clicked the "Next" button located at the bottom of the screen and proceeded to the second page of the Select Survey file.

\section{Mini Study 1: Evaluation of a Candidate Interview}

The second page of the Select Survey file informed participants that they were about to begin the first mini study. They were told that they would see an actual photo and job transcript from an actual job candidate interview, though the name of the candidate had been changed. Last, they were told that after the interview, they would be asked to recall information about the candidate and give their feedback regarding the candidate's qualifications. Participants were told to click "Next" when they were ready to begin their observation of the interview.

The third Select Survey page began the first of 17 question-and-answer pages that comprised the simulated job interview. Each page presented participants with a $342 \times 385$ pixel, color photo of one of four job candidate conditions: Tattooed male, Non-tattooed male, Tattooed female, or Non-tattooed female (Appendix). Below the photo, each page presented participants with two lines of 18-font, Calibri style text.

The first line represented the interviewer's question $(\mathrm{Q})$ and the second line represented the candidate's answer (A). Once participants read through both lines of text, they clicked "Next" to advance through each subsequent page of the interview. On each page, the photo of the job candidate remained the same, while the text below the photo 
differed from page to page. The simulated interview took participants approximately 10 minutes to complete.

\section{Mini Study 1: Measures}

After the interview, participants' memory was examined by presenting them with 10 questions that quizzed them on the content of the interview. Participants clicked "Next" to advance through each question, presented individually on separate pages. Participants clicked one of seven option buttons to submit their required answers for each question. The coefficient alpha for the 10-item memory scale was originally .57; however, removing a poor performing item (i.e. applicant's major) increased the 9-item coefficient alpha to .58 . The nine-item scale was used in all analyses pertaining to participant memory. Thoughts regarding the low coefficient alpha value are discussed in Limitations and Directions for Future Research.

Participants then advanced through 10 questions (one per page), asking them to evaluate the job candidate's overall effectiveness. For these questions, they clicked one of five option buttons, ranging from "Strongly agree" to "Strongly disagree," to submit their (required) answers. An attention check was placed halfway through the ten effectiveness evaluation questions, telling participants, "This is an attention check. Please select 'Strongly agree."' The coefficient alpha for the 10-item effectiveness scale was .90, and a post-hoc analysis of the items did not reveal any potential improvements to the scale's coefficient alpha per removal of any items. Both sets of questions (i.e. memory and overall effectiveness) can be found in the Appendix. 


\section{Mini Study 2: Evaluation of Abstract Art}

The next page informed participants that they were about to begin the second, unrelated mini study. They were further informed that they would be making some rapid judgments about abstract art, though in reality, this second study was identical to the AMP used in the pilot study (Appendix) and assessed their implicit attitudes towards tattoos. To reinforce the belief that the study was about abstract art (rather than tattoos), this page also gave participants a short description of varying attitudes towards abstract art.

Finally, this page informed participants that, because each abstract painting would only appear for one second, each would be preceded by a signal photo alerting them that the painting to be rated was about to appear. In line with the pilot study, participants were told that these photos were just signals and not to allow them to influence their judgments of the abstract paintings (Payne et al., 2005). By clicking "Next", participants were taken to the next page, where they were presented with the first signal photo, abstract painting, and message asking them to "Please Rate the Previous Painting."

\section{Mini-Study 2: Measures}

The first 12 pages involved paintings preceded by signal photos from the International Affective Picture System (Lang et al., 1995), which helped me compare the validity and reliability of my AMP data to AMP data used in other studies. The next 20 pages contained signal photos used in my pilot study, with ten photos containing images of tattooed individuals and the other ten containing images of non-tattooed individuals. 
Participants made their ratings by selecting one of six option buttons, ranging from "very unpleasant" to "very pleasant" (Appendix), and clicked "Next" to advance to the next series of images. The original coefficient alphas for the male, female, and overall AMP measures were $.536, .752$, and .759 , respectively, and a post hoc analysis indicated that the removal of any item would not add sufficient reliability to any of the three implicit scales.

\section{Additional Survey Questions}

After participants' completed the AMP, two pages containing manipulation checks were presented to ensure participants' recognition of the job applicant's (1) gender and (2) tattoo condition from the first mini study. The gender manipulation check asked participants, "In the first mini study, was Jessie (the job applicant) male or female?" Participants selected one of two gender option buttons before clicking "Next". The tattoo condition manipulation check asked participants, "In the first mini study, did Jessie display any of the following features: Piercings, Facial scars, Tattoos, Missing teeth, or None of the above?" Participants clicked a check box for each feature that they observed (though the tattoo condition was the only feature manipulated).

Next, participants' explicit attitudes towards tattooed men and tattooed women were assessed using two questions from the pilot study: "Generally, how do you feel about men with tattoos?" and "Generally, how do you feel about women with tattoos?" Participants indicated their feelings by picking one of eleven responses, ranging from "Extremely favorable feelings" to "Extremely unfavorable feelings." 
Last, participants answered five demographic questions which asked them about their: (a) own number of tattoos, (b) gender, (c) age, (d) ethnicity (1 = Caucasian/White, $2=$ African American/Black, $3=$ Asian American/Asian, $4=$ Indian American, $5=$ Other), and (e) level of education $(1=$ some high school, 2 = high school degree, $3=$ some college, $4=$ college degree, $5=$ some graduate school, $6=$ graduate degree, $7=$ Ph.D). Each demographic question was presented on a separate page. Collecting such demographic information allowed me to examine any individual differences that served as moderators of participants' implicit attitudes toward male and female tattooed and non-tattooed individuals.

After all questions were completed, participants were debriefed regarding the true nature of the survey, gave their consent for the use of their data, and were given a completion code allowing them to redeem their payment for participation using the MTurk website. 


\section{CHAPTER IV}

\section{ANALYSIS OF THE DATA}

\section{Attention Check, Manipulation Checks, and Outliers}

Of the 654 participants that completed the first mini study, 609 passed the attention check detailed in the Procedure and Design. Of this group, 578 passed the first manipulation check, correctly identifying the job applicant's gender. Of this group, 542 passed the second manipulation check, correctly identifying the job applicant as tattooed or non-tattooed. Participant data were only used if the participant passed both the attention check and two manipulation checks.

Using the Generalized Extreme Studentized Deviate (ESD) Test for Outliers (Rosner, 1983), two outliers were identified in data pertaining to the memory scale and two more in data pertaining to the implicit attitude scale (AMP). No outliers were found in data pertaining to the candidate rating scale or explicit attitude scale. Participants whose data yielded an outlier on either of the aforementioned scales were not used in the following analyses.

\section{Hypotheses}

Hypothesis 1: Tattooed (vs. non-tattooed) applicants will be rated lower on overall effectiveness. 
Overall effectiveness ratings were calculated by summing ratings for each of the ten effectiveness questions. Using these figures (and excluding outliers), an $F$ test was conducted with job applicant's tattoo condition (tattooed $=1$, non-tattooed $=0$ ) as the independent variable and participant ratings of the applicant's overall effectiveness as the dependent variable. Differences in participant effectiveness ratings for the tattooed applicants $(M=4.11, S D=.60)$ and non-tattooed applicants $(M=4.21, S D=.55)$ were found to be significant, $F(1,536)=4.49, p<.05$, partial $\eta^{2}=.01$. Thus, my first hypothesis was supported.

Hypothesis 2: There will be less recall of what is said in interviews with tattooed (vs. non-tattooed) applicants.

Participant recall was calculated by summing across nine memory questions $(1=$ correct, $0=$ incorrect), and an $F$ test was conducted with job applicant's tattoo condition (tattooed vs. non-tattooed) as the independent variable and participant recall (i.e. memory) as the dependent variable. The analysis did not find memory to be significantly greater when participants viewed a non-tattooed applicant $(M=7.15, S D=1.66)$ over a tattooed applicant $(M=6.93, S D=1.77), F(1,536)=2.14, p=.15, \eta^{2}=.004$. Thus, my second hypothesis could not be confirmed.

Hypothesis 3: Memory will mediate the relationship between tattoo condition and overall effectiveness ratings.

The results of the previous analysis brought into question whether memory could function as an appropriate mediator between tattoo condition and effectiveness ratings. Thus, in fully assessing my third hypothesis, it was first necessary to examine three 
assumptions: (1) tattoo condition predicts effectiveness ratings, (2) tattoo condition predicts participant recall, and (3) participant recall predicts effectiveness ratings.

Correlation coefficients were calculated for all three pair-wise relationships, and only the first (tattoo condition and effectiveness ratings) was found to be significant (Table 1).

Table 1

Correlations, Means, and Standard Deviations of Mediation Model Variables

\begin{tabular}{lcccc}
\hline Variable & $M$ & $S D$ & 1 & 2 \\
\hline 1. Tattoo Condition & -.04 & 1.0 & & \\
2. Participant Recall & 7.05 & 1.72 & -.06 & \\
3. Effectiveness Rating & 4.17 & .58 & $-.09 *$ & -.002 \\
\hline
\end{tabular}

Note: $* p<.05$

As I did not find significant correlations between each of my variables, I could not conclude participant recall to be a significant mediator of the relationship between tattoo condition and effectiveness ratings. A Sobel test also confirmed a lack of mediation in the model, $z=.15, \mathrm{p}=.88$ (Figure 1).

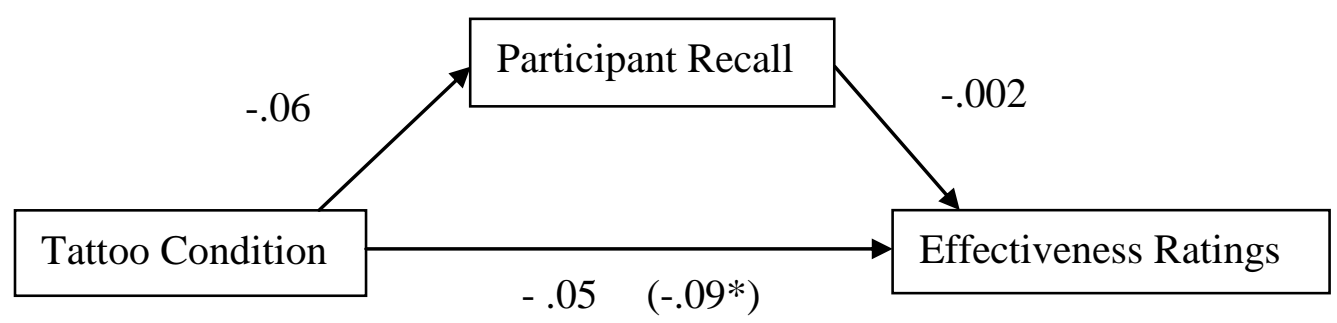

Figure 4. Standardized Regression Coefficients for the Relationship between Tattoo Condition and Effectiveness Ratings as Mediated by Participant Recall.

The standardized regression coefficient between tattoo condition and effectiveness ratings controlling for participant recall is in parentheses. $* p<.05$ 
Hypothesis 4: Applicant gender will moderate the mediation between tattoo condition and participant recall (i.e. memory), with participants remembering more information about tattooed females than tattooed males.

Having established that participant recall was not a statistically significant mediator of the tattoo condition-effectiveness ratings relationship, I next analyzed whether applicant gender was a significant moderator of the tattoo conditioneffectiveness ratings relationship (rather than the tattoo condition-participant recall relationship). Descriptive statistics and correlations among the predictor variable (tattoo condition), proposed moderator (participant gender), and criterion variable (effectiveness ratings) are found in Table 2.

Table 2 Correlations, Means, and Standard Deviations of Applicant Gender Moderation Analysis

\begin{tabular}{lcccc}
\hline Variable & $M$ & $S D$ & 1 & 2 \\
\hline 1. Tattoo Condition & -.04 & 1.0 & & \\
2. Applicant Gender & .06 & 1.0 & -.01 & \\
3. Effectiveness Rating & 4.17 & .58 & $-.09^{*}$ & .02 \\
\hline
\end{tabular}
Note: $* p<.05$

A hierarchical multiple regression analysis was conducted with tattoo condition entered in the first step; tattoo condition and applicant gender entered in the second step; and tattoo condition, applicant gender, and the interaction of tattoo condition and applicant gender in the third step.

The second step of my analysis revealed that the addition of applicant gender did not result in a significant increase in explained variance, $\Delta R^{2}<.001, \Delta F(2,535)=.14, p$ $=.71$. In the third step, I observed that the interaction of tattoo condition and applicant 
gender also did not explain a significant increase in variance in effectiveness ratings, $\Delta R^{2}$

$<.001, \Delta F(3,534)=.12, p=.73$. Thus, applicant gender did not moderate the relationship between tattoo condition and effectiveness ratings (Table 3).

Table 3

Analysis of Applicant Gender as a Moderator of Tattoo Condition and Effectiveness Ratings

\begin{tabular}{|c|c|c|c|c|c|c|c|}
\hline Variable & $B$ & $S E B$ & $\beta$ & $t$-value & $R^{2}$ & $\Delta R^{2}$ & $\Delta F$ \\
\hline \multicolumn{8}{|l|}{$\begin{array}{l}\text { Effectiveness } \\
\text { ratings }\end{array}$} \\
\hline $\begin{array}{l}\text { Step } 1 \\
\text { Tattoo }\end{array}$ & -.05 & .03 & -.09 & -2.12 & .008 & .008 & $4.49 *$ \\
\hline Condition & & & & & & & \\
\hline $\begin{array}{l}\text { Step } 2 \\
\text { Tattoo }\end{array}$ & -.05 & .03 & -.09 & -2.12 & .009 & $<.001$ & .14 \\
\hline $\begin{array}{l}\text { Condition } \\
\text { Applicant } \\
\text { Gender }\end{array}$ & .009 & .03 & .016 & .37 & & & \\
\hline $\begin{array}{l}\text { Step } 3 \\
\text { Tattoo }\end{array}$ & -.05 & .03 & -.09 & -2.11 & .009 & $<.001$ & .12 \\
\hline $\begin{array}{l}\text { Condition } \\
\text { Applicant }\end{array}$ & .009 & .03 & .016 & .37 & & & \\
\hline $\begin{array}{l}\text { Gender } \\
\text { Interaction }\end{array}$ & -.009 & .03 & -.015 & -.35 & & & \\
\hline
\end{tabular}

Note: $* p<.05$

Hypothesis 5: Implicit tattoo-related attitudes will moderate participant recall with people who have more negative implicit attitudes about tattooed individuals recalling less than people who have more positive implicit attitudes.

Next, a hierarchical multiple regression analysis was conducted examining whether participants' implicit attitudes towards tattooed individuals moderated the tattoo condition-effectiveness ratings relationship. Descriptive statistics and correlations among 
the predictor variable (tattoo condition), proposed moderator (implicit attitudes), and criterion variable (effectiveness ratings) are found in Table 4.

Table 4

Correlations, Means, and Standard Deviations of Implicit Attitude Moderation Analysis

\begin{tabular}{lcccc}
\hline Variable & $M$ & $S D$ & 1 & 2 \\
\hline 1. Tattoo Condition & -.04 & 1.0 & & \\
2. Implicit Attitudes & .67 & .84 & -.001 & \\
3. Effectiveness Rating & 4.17 & .58 & $-.09 *$ & .05 \\
\hline
\end{tabular}

Note: $* p<.05$

The second step of my analysis revealed that implicit attitudes did not explain significant new variance in participant effectiveness ratings, $\Delta R^{2}=.002, \Delta F(2,437)=$ $.96, p=.33$. However, the interaction between implicit attitudes and tattoo condition did show a significant increase in explained variance in effectiveness ratings, $\Delta R^{2}=.009$, $\Delta F(3,436)=4.12, p<.05$, with participants who had more negative implicit attitudes about tattooed individuals giving lower effectiveness ratings than participants with more positive implicit attitudes. Thus, implicit attitudes were found to be a significant moderator of the relationship between tattoo condition and effectiveness ratings (Table $5)$. 
Table 5

Analysis of Implicit Attitudes as a Moderator of Tattoo Condition and Effectiveness Ratings

\begin{tabular}{|c|c|c|c|c|c|c|c|}
\hline & $B$ & $S E B$ & $\beta$ & $t$-value & $R^{2}$ & $\Delta R^{2}$ & $\Delta F$ \\
\hline \multicolumn{8}{|l|}{ Effectiveness } \\
\hline $\begin{array}{l}\text { Step } 1 \\
\text { Tattoo }\end{array}$ & -.05 & .03 & -.09 & -1.79 & .007 & .007 & 3.21 \\
\hline Condition & & & & & & & \\
\hline $\begin{array}{l}\text { Step } 2 \\
\text { Tattoo }\end{array}$ & -.05 & .03 & -.09 & -2.07 & .009 & .002 & .96 \\
\hline $\begin{array}{l}\text { Condition } \\
\text { Implicit } \\
\text { Attitudes }\end{array}$ & .03 & .03 & .05 & .99 & & & \\
\hline $\begin{array}{l}\text { Step } 3 \\
\text { Tattoo }\end{array}$ & -.05 & .03 & -.09 & -1.85 & .019 & .009 & $4.12 *$ \\
\hline $\begin{array}{l}\text { Condition } \\
\text { Implicit }\end{array}$ & .02 & .03 & .03 & .60 & & & \\
\hline $\begin{array}{l}\text { Attitudes } \\
\text { Interaction }\end{array}$ & .06 & .03 & .10 & 2.03 & & & \\
\hline
\end{tabular}

Note: $* p<.05$

A post-hoc analysis was conducted to assess whether memory may, in fact, have served as a mediator of tattoo condition and effectiveness ratings at a high $(N=222, M=$ $1.23, S D=.40)$ and/or low $(N=220, M=.10, S D=.77)$ level of implicit attitudes;

however, Sobel tests did not find evidence of mediation at either the high $(z=-.46, p=$ $.64)$ or low $(z=.53, p=.60)$ levels.

\section{Exploratory Analysis of Demographic Moderators}

Post-hoc analyses also examined a number of additional potential moderators of the tattoo condition-effectiveness ratings relationship, including participant: (a) explicit attitudes regarding tattoos, (b) age, (c) number of tattoos, (d) gender, (e) ethnicity, and (f) level of education. 


\section{Explicit Attitudes}

My first post-hoc hierarchical multiple regression analysis examined whether explicit attitudes, similar to implicit attitudes, served as a moderator of the tattoo condition-effectiveness ratings relationship. Descriptive statistics and correlations among the predictor variable (tattoo condition), proposed moderator (explicit attitudes), and criterion variable (effectiveness ratings) are found in Table 6.

Table 6 Correlations, Means, and Standard Deviations of Explicit Attitude Moderation Analysis

\begin{tabular}{lcccc}
\hline Variable & $M$ & $S D$ & 1 & 2 \\
\hline 1. Tattoo Condition & -.04 & 1.0 & & \\
2. Explicit Attitudes & 6.63 & 2.05 & .06 & \\
3. Effectiveness Rating & 4.17 & .58 & $-.09 *$ & $.17 * *$ \\
\hline
\end{tabular}

Note: $* p<.05 * * p<.001$

The second step of the analysis revealed that explicit attitudes did explain significant new variance in participant effectiveness ratings, $\Delta R^{2}=.030, \Delta F(2,506)=$ $15.9, p<.001$. Likewise, the interaction between explicit attitudes and tattoo condition showed a significant increase in explained variance in effectiveness ratings, $\Delta R^{2}=.014$, $\Delta F(3,505)=7.34, p<.01$, with participants who had more negative explicit attitudes about tattooed individuals giving lower effectiveness ratings than participants with more positive explicit attitudes. Thus, explicit attitudes were found to be a significant moderator of the tattoo condition-effectiveness ratings relationship (Table 7). 
Table 7

Analysis of Explicit Attitudes as a Moderator of Tattoo Condition and Effectiveness Ratings

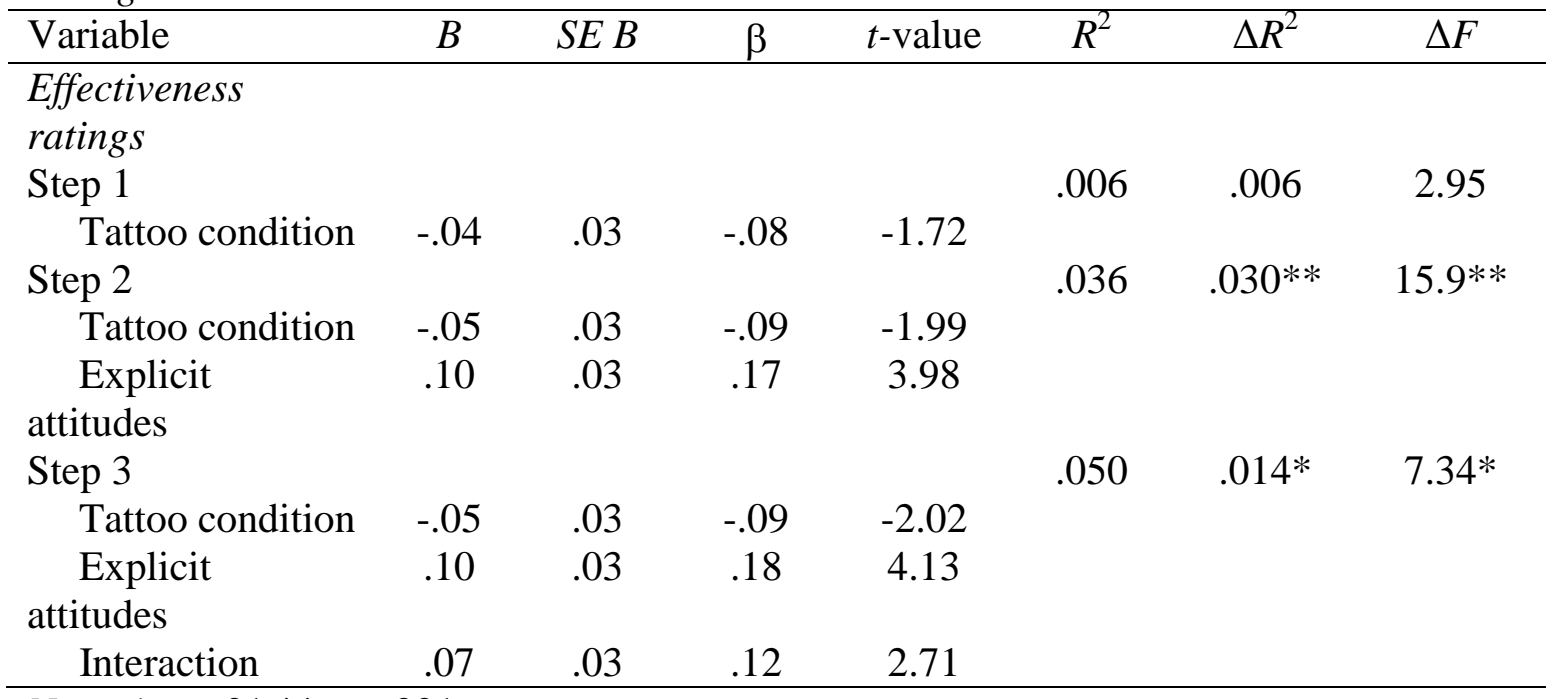

Note: $* p<.01 * * p<.001$

Participant Age

A hierarchical multiple regression analysis was next conducted to assess whether participant age served as a moderator of the tattoo condition-effectiveness ratings relationship. Descriptive statistics and correlations among the predictor variable (tattoo condition), proposed moderator (participant age), and criterion variable (effectiveness ratings) are found in Table 8.

Table 8 Correlations, Means, and Standard Deviations of Participant Age Moderation Analysis

\begin{tabular}{lcccc} 
Variable & $M$ & $S D$ & 1 & 2 \\
\hline 1. Tattoo Condition & -.04 & 1.0 & & \\
2. Participant Age & 32.0 & 12.2 & -.02 & \\
3. Effectiveness Rating & 4.17 & .58 & $-.09^{*}$ & $-.15^{* *}$ \\
\hline
\end{tabular}

Note: $* p<.05 * * p<.01$ 
The analysis revealed that the addition of participant age explained significant new variance in participant effectiveness ratings, $\Delta R^{2}=.022, \Delta F(2,533)=12.3, p<.001$. However, the interaction between participant age and tattoo condition did not result in a significant increase in explained variance in effectiveness ratings, $\Delta R^{2}<.001, \Delta F(3,532)$ $=.12, p=.73$. Thus, participant age was found to be an additional predictor of effectiveness ratings rather than a moderator of the tattoo condition-effectiveness ratings relationship (Table 9).

Table 9

Analysis of Participant Age as a Moderator of Tattoo Condition and Effectiveness Ratings

\begin{tabular}{lccccccc}
\hline Variable & $B$ & $S E B$ & $\beta$ & $t$-value & $R^{2}$ & $\Delta R^{2}$ & $\Delta F$ \\
\hline $\begin{array}{l}\text { Effectiveness } \\
\text { ratings }\end{array}$ & & & & & & & \\
Step 1 & & & & & .008 & $.008^{*}$ & $4.42^{*}$ \\
$\quad$ Tattoo condition & -.05 & .03 & -.09 & -2.10 & & & \\
Step 2 & & & & & .031 & $.02^{* *}$ & $12.3^{* *}$ \\
$\quad$ Tattoo condition & -.05 & .03 & -.09 & -2.19 & & & \\
$\quad$ Participant age & -.09 & .03 & -.15 & -3.50 & & & \\
Step 3 & & & & & .031 & .00 & .122 \\
$\quad$ Tattoo condition & -.05 & .03 & -.09 & -2.19 & & & \\
$\quad$ Participant age & -.09 & .03 & -.15 & -3.50 & & & \\
$\quad$ Interaction & .01 & .03 & .02 & .35 & & & \\
\hline
\end{tabular}

Note: $* p<.05 * p<.001$

\section{Number of Tattoos}

My next hierarchical multiple regression analysis assessed whether participants' number of tattoos could serve as a moderator of the tattoo condition-effectiveness ratings relationship. Descriptive statistics and correlations among the predictor variable (tattoo condition), proposed moderator (number of tattoos), and criterion variable (effectiveness ratings) are found in Table 10. 
Table 10

Correlations, Means, and Standard Deviations of Number of Tattoos Moderation Analysis

\begin{tabular}{lcccc} 
Variable & $M$ & $S D$ & 1 & 2 \\
\hline 1. Tattoo Condition & -.04 & 1.0 & & \\
2. Number of Tattoos & .76 & 1.64 & .04 & \\
3. Effectiveness Rating & 4.17 & .58 & $-.09^{*}$ & $.10^{*}$
\end{tabular}

Note: $* p<.05$

The present analysis revealed that the addition of participants' number of tattoos explained significant new variance in participant effectiveness ratings, $\Delta R^{2}=.012, \Delta F(2$, $533)=6.26, p<.05$. However, the interaction between number of tattoos and tattoo condition did not show a significant increase in explained variance in effectiveness ratings, $\Delta R^{2}<.001, \Delta F(3,532)=.021, p=.89$. Thus, participants' number of tattoos were found to be an additional predictor of effectiveness ratings rather than a significant moderator (Table 11).

Table 11

Analysis of Number of Tattoos as a Moderator of Tattoo Condition and Effectiveness Ratings

\begin{tabular}{lccccccc}
\hline Variable & $B$ & $S E B$ & $\beta$ & $t$-value & $R^{2}$ & $\Delta R^{2}$ & $\Delta F$ \\
\hline $\begin{array}{l}\text { Effectiveness } \\
\text { ratings }\end{array}$ & & & & & & & \\
$\quad$ Step 1 & & & & & .008 & $.008^{*}$ & $5.28^{*}$ \\
$\quad$ Tattoo condition & -.05 & .03 & -.09 & -2.10 & & & \\
$\quad \begin{array}{l}\text { Step 2 } \\
\quad\end{array}$ & & & & .020 & $.012^{*}$ & $6.26^{*}$ \\
$\quad$ Tattoo condition & -.06 & .03 & -.10 & -2.22 & & & \\
$\quad$ Num. of tattoos & .06 & .03 & .11 & 2.50 & & & \\
Step 3 & & & & & .020 & .00 & .021 \\
$\quad$ Tattoo condition & -.06 & .03 & -.10 & -2.21 & & & \\
$\quad$ Num. of tattoos & .06 & .03 & .11 & 2.46 & & & \\
$\quad$ Interaction & .00 & .03 & .006 & .14 & & & \\
\hline
\end{tabular}

Note: $* p<.05$ 


\section{Participant Gender}

My next hierarchical multiple regression analysis assessed whether participant gender served as a moderator of the tattoo condition-effectiveness ratings relationship. Descriptive statistics and correlations among the predictor variable (tattoo condition), proposed moderator (participant gender), and criterion variable (effectiveness ratings) are found in Table 12.

Table 12

Correlations, Means, and Standard Deviations of Participant Gender Moderation Analysis

\begin{tabular}{lcccc}
\hline Variable & $M$ & $S D$ & 1 & 2 \\
\hline 1. Tattoo Condition & -.04 & 1.0 & & \\
2. Participant Gender & 1.43 & .50 & .08 & \\
3. Effectiveness Rating & 4.17 & .58 & $-.09 *$ & $-.10^{*}$ \\
\hline
\end{tabular}

Note: $* p<.05$

The analysis revealed that the addition of participant gender explained a significant amount of new variance in participant effectiveness ratings, $\Delta R^{2}=.008, \Delta F(2$, $530)=4.47, p<.05$. Moreover, the interaction between participant gender and tattoo condition also showed a significant increase in explained variance in effectiveness ratings, $\Delta R^{2}=.007, \Delta F(3,529)=3.86, p=.05$. Thus, participant gender was found to be a significant moderator of the tattoo condition-effectiveness ratings with the manipulation being more effective for male participants $(F[1,229]=6.68, p=.01)$ than female participants $(F[1,304]=.05, p=.83)$. 
Table 13

Analysis of Participant Gender as a Moderator of Tattoo Condition and Effectiveness Ratings

\begin{tabular}{|c|c|c|c|c|c|c|c|}
\hline Variable & $B$ & $S E B$ & $\beta$ & $t$-value & $R^{2}$ & $\Delta R^{2}$ & $\Delta F$ \\
\hline \multicolumn{8}{|l|}{ Effectiveness } \\
\hline Step 1 & & & & & .010 & $.010 *$ & $5.10 *$ \\
\hline Tattoo condition & -.06 & .03 & -.10 & -2.26 & & & \\
\hline Step 2 & & & & & .018 & $.008 *$ & $4.47 *$ \\
\hline Tattoo condition & -.05 & .03 & -.09 & -2.10 & & & \\
\hline Part. gender & -.05 & .03 & -.09 & -2.12 & & & \\
\hline Step 3 & & & & & .025 & .007 & 3.85 \\
\hline Tattoo condition & -.05 & .03 & -.09 & -2.10 & & & \\
\hline Part. gender & -.05 & .03 & -.09 & -2.07 & & & \\
\hline Interaction & -.05 & .03 & -.08 & -1.96 & & & \\
\hline
\end{tabular}

Note: $* p<.05$

\section{Ethnicity}

A two-way ANOVA was performed examining the relationship between tattoo condition and ethnicity as predictors of candidate effectiveness ratings. The main effect of tattoo condition, without the eight degrees of freedom afforded to it in the first hypothesis, this time yielded an $F$ ratio of $F(1,528)=2.08, p=.15$, partial $\eta^{2}=.004$, indicating that candidate effectiveness ratings were not significantly greater for nontattooed applicants $(M=4.22, S D=.55)$ than for tattooed applicants $(M=4.11, S D=.60)$ when examined together with ethnicity. The main effect of ethnicity yielded an $F$ ratio of $F(4,528)=1.20, p=.31$, partial $\eta^{2}=.009$, indicating that candidate effectiveness ratings were not significantly higher at any ethnicity level (Table 14). The interaction effect was also non-significant, $F(4,528)=1.04, p=.39$, partial $\eta^{2}=.008$. 
Table 14

Descriptive Statistics of Effectiveness Ratings at Each Ethnicity Level

\begin{tabular}{lccc}
\hline Variable & $N$ & $M$ & $S D$ \\
\hline Caucasian/White & 427 & 4.18 & .56 \\
African American/Black & 48 & 4.13 & .67 \\
Asian American/Asian & 34 & 3.97 & .70 \\
Indian American & 3 & 4.17 & .15 \\
Other & 26 & 4.28 & .61 \\
Total & 538 & 4.17 & .58 \\
\hline
\end{tabular}

\section{Level of Education}

A final hierarchical multiple regression analysis examined whether participant level of education $(1=$ some high school, $2=$ high school degree, $3=$ some college, $4=$ college degree, $5=$ some graduate school, $6=$ graduate degree, $7=\mathrm{Ph} . \mathrm{D})$ served as a moderator of the tattoo condition-effectiveness ratings relationship. Descriptive statistics and correlations among the predictor variable (tattoo condition), proposed moderator (level of education), and criterion variable (effectiveness ratings) are found in Table 15.

Table 15

Correlations, Means, and Standard Deviations of Level of Education Moderation Analysis

\begin{tabular}{lcccc}
\hline Variable & $M$ & $S D$ & 1 & 2 \\
\hline 1. Tattoo Condition & -.04 & 1.00 & & \\
2. Level of Education & 3.77 & 1.18 & .08 & \\
3. Effectiveness Rating & 4.17 & .58 & $-.09 *$ & $-.22 * *$ \\
\hline
\end{tabular}

Note: $* p<.05 * * p<.01$

This final analysis revealed that level of education explained significant new variance in participant effectiveness ratings, $\Delta R^{2}=.044, \Delta F(2,533)=24.7, p<.001$. However, the interaction between level of education and tattoo condition did not show a significant increase in explained variance in effectiveness ratings, $\Delta R^{2}=.003, \Delta F(3,532)$ 
$=1.81, p=.18$. Thus, level of education was found to be an additional predictor of effectiveness ratings rather than a significant moderator (Table 16).

Table 16

Analysis of Level of Education as a Moderator of Tattoo Condition and Effectiveness Ratings

\begin{tabular}{|c|c|c|c|c|c|c|c|}
\hline Variable & $B$ & $S E B$ & $\beta$ & $t$-value & $R^{2}$ & $\Delta R^{2}$ & $\Delta F$ \\
\hline \multicolumn{8}{|l|}{$\begin{array}{l}\text { Effectiveness } \\
\text { ratings }\end{array}$} \\
\hline Step 1 & & & & & .008 & $.008^{*}$ & $4.42 *$ \\
\hline Tattoo condition & -.05 & .03 & -.09 & -2.10 & & & \\
\hline Step 2 & & & & & .052 & $.044 * *$ & $24.7 * *$ \\
\hline Tattoo condition & -.04 & .03 & -.07 & -1.75 & & & \\
\hline Education level & -.12 & .03 & -.21 & -5.00 & & & \\
\hline Step 3 & & & & & .055 & .003 & 1.81 \\
\hline Tattoo condition & -.04 & .03 & -.07 & -1.74 & & & \\
\hline Education level & -.12 & .03 & -.21 & -4.98 & & & \\
\hline Interaction & -.03 & .03 & -.06 & -1.35 & & & \\
\hline
\end{tabular}

Note: $* p<.05 * * p<.001$ 


\section{CHAPTER V \\ SUMMARY AND CONCLUSIONS}

Madera and Hebl (2011) were among the first researchers to examine the specific processes involved in the discrimination of physically stigmatized individuals in job interviews. In their research, they found that participants evaluating stigmatized job applicants remembered less information from the job interview, which directly led to participants' rating stigmatized individuals lower in overall effectiveness than nonstigmatized individuals. These findings were important in that they connected stigma research to the study of biases and discrimination in the job interview - one of the most widely utilized methods for employee selection (Campion, Palmer, \& Campion, 1997). Still, their research encompassed only one type of stigmatizing condition - facial stigmas. Thus, their findings opened the door for a number of future studies on the discrimination of other stigmatizing conditions.

Pryor and Reeder (2011) indicated that a hallmark of a stigma is that it evokes implicit negative attitudes. In a pilot study, a tattoo stigma was found to exist in that tattooed individuals were evaluated more negatively than non-tattooed individuals at both the explicit and implicit levels. The present study examined whether this stigma, like Madera \& Hebl's study, could also resulted in job applicant discrimination in the evaluation of tattooed job applicants. 
Five hypotheses were tested in addition to some exploratory analyses. First, I hypothesized that tattooed job applicants would be rated lower than non-tattooed applicants in overall effectiveness ratings, and this hypothesis was confirmed. Second, I hypothesized that there would be less recall (i.e. memory) of what was said in interviews with tattooed applicants than non-tattooed applicants. This hypothesis was not confirmed. Third, I hypothesized that memory would mediate the relationship between tattoo condition and overall effectiveness ratings. This hypothesis was also not confirmed.

My next two hypotheses were originally set up to examine two potential moderators of the tattoo condition-participant recall relationship: applicant gender and participant implicit attitudes. However, as participant recall was not found to be a significant mediator of the tattoo condition-effectiveness ratings relationship, the analyses were simplified to examine applicant gender and implicit attitudes as potential moderators of the tattoo condition-effectiveness ratings relationship instead. Applicant gender was not found to be a significant moderator the relationship; however implicit attitudes was, with participants who had more negative implicit attitudes about tattooed individuals giving significantly lower effectiveness ratings than participants with more positive implicit attitudes.

Finally, a number of exploratory analyses were performed post-hoc to examine whether participants' (a) explicit attitudes, (b) number of tattoos, (c) gender, (d) age, (e) ethnicity, and/or (f) level of education served as moderators of the tattoo conditioneffectiveness ratings relationship. Explicit attitudes and participant gender were found to be predictors and moderators of the relationship, with (a) participants who had more 
negative explicit attitudes about tattooed individuals giving lower effectiveness ratings than participants with more positive explicit attitudes and (b) the tattoo manipulation being more effective for male participants than female participants.

When testing both (AMP-based) implicit attitudes and (feeling thermometerbased) explicit attitudes in the same equation, the overall equation was highly significant, $\Delta R^{2}=.04, \Delta F(2,416)=7.99, p<.001$. Explicit ratings were superior to implicit ratings in accounting for unique variance in candidate effectiveness ratings, $\beta=.21, t(416)=$ $4.00, p<.001$ and $\beta=-.08, t(416)=-1.50, p=.14$, respectively. When testing all significant moderators (i.e. implicit attitudes, explicit attitudes, and participant gender) in the same equation, the overall equation was again highly significant, $\Delta R^{2}=.04, \Delta F(3$, $415)=5.59, p=.001$. Explicit ratings were again superior to implicit ratings and participant gender in accounting for unique variance in candidate effectiveness ratings, $\beta$ $=.19, t(416)=3.66, p<.001, \beta=-.08, t(416)=-1.54, p=.12$, and $\beta=-.06, t(416)=-$ $1.12, p=.27$, respectively.

Participants' age, number of tattoos, and level of education were all found to be significant predictors of effectiveness ratings rather than moderators of the tattoo condition-effectiveness ratings relationship. Ethnicity did not prove to be a significant predictor of effectiveness ratings nor a significant moderator of the tattoo conditioneffectiveness ratings relationship. Figure 2 illustrates each significant relationship identified in this study. 


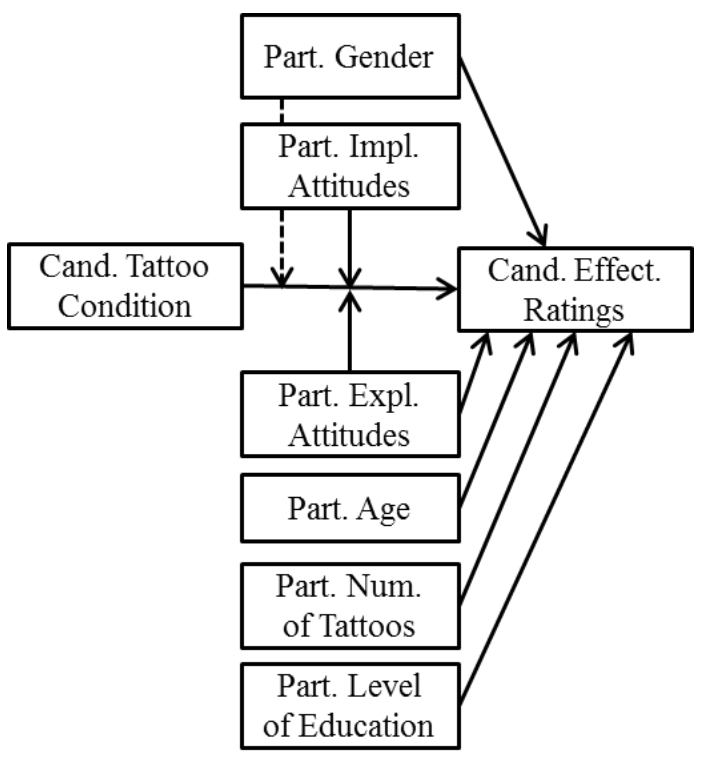

Figure 5. Variables Influencing Candidate Effectiveness Ratings.

Solid line: $p<.05$. Dotted line: $p=.05$. 


\section{CHAPTER VI \\ LIMITATIONS AND DIRECTIONS FOR FUTURE RESEARCH}

Perhaps the most surprising finding in the present study was that, unlike the results found in Madera \& Hebl (2011), memory did not prove to be a significant mediator of the stigma condition-effectiveness ratings relationship. I see two possible explanations for this finding. First, the stigmatizing (i.e. tattoo) condition used for the present study was more concealable (i.e. applicant's arm rather than face) than that used by Madera \& Hebl. Second, rather than watching an actual interview, participants in the present study read through a script presented below static images, which may have taken their attention away from the stigmatizing condition.

\section{Level of Concealability}

As most observers concentrate on the face of a job applicant (rather than arm) during an interview, it is likely that the tattoo proved less stigmatizing than a facial stigma, and thus, had less of an effect on participant recall. However, had the tattoo been placed on the face or neck, it may have proved just as stigmatizing as a port wine stain/scar. As was recognized by Bell (1999) and Roberts (2012), the latter who noted that "not all tattooed bodies are equal in American culture," differences in tattoo placement can result in a distinction between "people with tattoos" and "tattooed people." Specifically, Roberts found that "people with tattoos" is often used to describe 
individuals who "have one to a few tattoos strategically placed on areas of their bodies that are easily hidden;" alternatively, "tattooed people" is used to describe individuals who "get tattoos that are always visible to others" (p. 153).

Two factors seem to lie at the heart of such a distinction: tattoo number and placement. Regarding number, Totten et al. (2009) found that $85.3 \%$ of respondents agreed that the number of tattoos a person has makes a difference in how he or she is perceived by others (p. 92). They also found that tattoos can be attractive "as long as these are not overdone" (p. 93). Regarding placement, Totten and his colleagues found that "small, discrete" tattoos were seen as highly attractive (p. 86), while "extensive tattoos" are usually not seen as attractive (p. 83).

Though Madera and Hebl were able to confirm discrimination of visibly stigmatized applicants, they limited their study to a very small percentage of individuals with visible stigmas - individuals with prominent facial marks/scars. While highly stigmatizing, studies show that port wine stains/prominent facial scars are found in less than $1 \%$ of the population (Barsky et al., 1980). Tattoos, on the other hand, can be seen in 40\% of 21-31 year olds today (Martin \& Dula, 2010). Therefore, research examining more popular, though notably more subtle stigmatizing conditions may prove more beneficial to our understanding of stigma evaluation overall.

Animated vs. Static Interview Visuals

A second possible explanation for why the present study did not find memory to be a mediator of the tattoo condition-effectiveness ratings relationship may relate to how the study was conducted. Specifically, participants in the present study were presented 
with a static image of a job applicant with text of the interview appearing below the static image. It may have been possible that participants looked at the static image at the beginning of the interview then saw no reason to pay further attention to the image as they advanced from one page of the interview to the next. Such occurrences may also have contributed to the low memory scale coefficient alpha. If this were the case, future studies may find it advantageous to use a more realistic simulated interview, such as an animated clip, instead of using static images.

\section{Madera \& Hebl Techniques for Other Stigmas}

Another limitation of the present study is that it only examined one form of interview discrimination resulting from stigma - tattoo. Future studies may wish to utilize the procedures detailed in Madera \& Hebl (2011) in an effort to examine other visibly stigmatizing conditions (e.g. ethnic minority, obesity, piercings). Studies in this vein may find memory to be a significant mediator of effectiveness ratings or not, creating a more complete picture of the both the physical and cognitive factors underlying stigma evaluation and discriminatory consequences. Moreover, such studies are likely to benefit from advances in 3D imaging technology that are allowing the manipulation of avatar physical factors (e.g. height, weight, ethnicity) to be increasingly realistic and easy to do.

\section{Tattoo Research}

In the current study, participants were only asked to evaluated job applicants who were recent college graduates. However, future studies may find it useful to vary the age and/or level of education of the job applicant. Research has shown that tattooed adolescents are rated less positively than tattooed adults (Stuppy et al., 1998). Totten et 
al. (2009) found similar results, with only $24.2 \%$ of participants expressing that "tattoos are appropriate for a person of any age" compared with $60.9 \%$ who disagreed with such a statement (p. 89). Future studies may wish to examine potential differences in (1) the evaluation of tattooed-adolescence and/or (2) adolescent evaluations of tattooed individuals.

Lastly, future studies may find it advantageous to examine regional and/or national differences in the evaluation of tattooed job applicants. Totten et al. (2009) found that a higher percentage of participants from the East Coast region of the U.S. agreed that tattoos are attractive $(87.3 \%)$ as compared to those in the Pacific, Midwestern, and Southern regions $(61.4 \%$; p. 88). Future studies could perform an examination of regional differences in tattoo-related attitudes by grouping participants by IP addresses and conducting an analysis of variance across groups. 


\section{REFERENCES}

Adams, J. (2012). Cleaning up the dirty work: Professionalization and the management of stigma in the cosmetic surgery and tattoo industries. Deviant Behavior, 33, 149167.

Angermeyer, M. C., Schulze, B., \& Dietrich. S. (2003). Courtesy stigma: A focus group study of relatives of schizophrenia patients. Social Psychiatry and Psychiatric Epidemiology, 38, 593-602.

Armstrong, M. L. (1991). Career-oriented women with tattoos. Journal of Nursing Scholarship, 23, 215-220.

Atkinson, M. (2003). Tattooed: The sociogenesis of a body art. Toronto, Ontario, Canada: University of Toronto Press.

Baddeley, A. D., \& Hitch, G. (1974). Working memory. In G. H. Bower (Ed.), The psychology of learning and motivation: Advances in research and theory (Vol. 8, pp. 47-89). New York, NY: Academic Press.

Baron, R. A. (1983). Sweet smell of success? The impact of pleasant artificial scents on evaluation of job applicants. Journal of Applied Psychology, 68, 709-713.

Barsky, S. H., Rosen, S., Geer, D. E., \& Noe, J. M. (1980). The nature and evolution of port wine stains: A computer-assisted study. Journal of Investigative Dermatology, 74, 154-157.

Bassett, J. F., \& Dabbs, J. M. (2005). A portable version of the go/no-go association task (GNAT). Behavior Research Methods, Instruments, and Computers, 37, 506-512.

Bell, S. (1999). Tattooed: A participant observer's exploration of meaning. Journal of American Culture, 22(2), 53-58.

Bessenoff, G. R., \& Sherman, J. W. (2000). Automatic and controlled components of prejudice toward fat people: Evaluation versus stereotype activation. Social Cognition, 18, 329-353.

Birenbaum, A. (1992). Courtesy stigma revisited. Mental Retardation, 30, 265-268. 
Blascovich, J., Mendes, W. B., Hunter, S. B., Lickel, B., \& Kowai-Bell, N. (2001). Perceiver threat in social interactions with stigmatized others. Journal of Personality and Social Psychology, 80(2), 253-267.

Brenner, L., von Hippel, W., \& Kippax, S. (2007). Prejudice among health care workers toward injecting drug users with hepatitis C: Does greater contact lead to less prejudice? The International Journal of Drug Policy, 18, 381-387.

Buhrmester, M., Kwang, T., \& Gosling, S. D. (2011). Amazon's Mechanical Turk: A new source of inexpensive, yet high quality, data? Perspectives on Psychological Science, 6, 3-5.

Burgess, M., \& Clark, L. (2010). Do the "savage origins" of tattoos cast a prejudicial shadow on contemporary tattooed individuals? Journal of Applied Social Psychology, 40(3), 746-764.

Campion, M. A., Palmer, D. K., \& Campion, J. E. (1997). A review of structure in the selection interview. Personnel Psychology, 50, 655-702.

Chaudoir, S. R., \& Quinn, D. M. (2010). Revealing concealable stigmatized identities: The impact of disclosure motivations and positive first-disclosure experiences on fear of disclosure and well-being. Journal of Social Issues, 66(3) 570-584.

Christensen, M. H. (2000). Photo essay: Tattoos. Public Health Reports, 115(5), 430-435.

Corrigan, P. W., Watson, A. C., \& Miller, F. E. (2006). Blame, shame, and contamination: The impact of mental illness and drug dependence stigma on family members. Journal of Family Psychology, 20, 239-246.

Crandall, C. S., \& Eshleman, A. (2003). A justification-suppression of the expression and experience of prejudice. Psychological Bulletin, 129, 414-446.

Crocker, J., Major, B., \& Steele, C. (1998). Social stigma. In The handbook of social psychology, 2, 504-553.

Dean, D. H. (2010). Consumer perceptions of visible tattoos on service personnel. Managing Service Quality, 20(3), 294-308.

Dean, D. H. (2011). Young adult perception of visible tattoos on white-collar service provider. Young Consumers: Insight and Ideas for Responsible Marketers, 12(3), 254-264.

DeMello, M. (2000). Bodies of Incription: A Cultural History of the Modern Tattoo Community. Durham, NC: Duke University Press. 
Dipboye, R. L. (2005). The selection/recruitment interview: Core processes and contexts. In A. Evers, N. Anderson, \& O. Smit-Voskuijl (Eds.), The Blackwell handbook of personnel selection (pp. 121-142). Malden, MA: Blackwell.

Dipboye, R. L., \& Collela, A. (2005). Discrimination at work: The psychological and organizational bases. Mahwah, NJ: Erlbaum.

Dunton, B. C., \& Fazio, R. H. (1997). An individual difference measure of motivation to control prejudice reactions. Personality and Social Psychology Bulletin, 23(3), 316-326.

Goffman, E. (1963). Stigma: Notes on the management of spoiled identity. New York, NY: Prentice Hall.

Grandfield, T. A., Thomson, A., \& Turpin, G. (2005). An attitudinal study of responses to a range of dermatological conditions using the Implicit Association Test. Journal of Health Psychology, 10, 821-829.

Greenwald, A. G., McGhee, D. E., \& Schwartz, J. K. L. (1998). Measuring individual differences in implicit cognition: The implicit association test. Journal of Personality and Social Psychology, 74, 1464-1480.

Hawkes, D. Senn, C. Y., \& Thorn, C. (2004). Factors that influence attitudes toward women with tattoos. Sex Roles, 50(9-10), 593-604.

Hebl, M. R., \& Mannix, L. M. (2003). The weight of obesity in evaluating others: A mere proximity effect. Personality and Social Psychology Bulletin, 29, 28-38.

Heywood, W., Patrick, K., Smith, A. M. A, Simpson, J. M., Pitts, M. K., Richters, J., \& Shelley, J. M. (2012). Who gets tattoos? Demographics and behavioral correlates of ever being tattooed in a representative sample of men and women. Ann Epidemiol, 22, 51-56.

Houston, V., \& Bull, R. (1994). Do people avoid sitting next to someone who is facially disfigured? European Journal of Social Psychology, 24, 279-284.

Huffcutt, A. I., \& Arthur, W., Jr. (1994). Hunter and Hunter (1984) revisited: Interview validity for entry-level jobs. Journal of Applied Psychology, 79, 184-190.

Hunter, J. E., \& Hunter, R. F. (1984). Validity and utility of alternative predictors of job performance. Psychological Bulletin, 96, 72-98.

Jellison, W. A., McConnell, A. R., \& Gabriel, S. (2004). Implicit and explicit measures of sexual orientation attitudes: Ingroup preferences and related behaviors and 
beliefs among gay and straight men. Personality and Social Psychology Bulletin, $30,629-642$.

Johnson, K. K. P., \& Roach-Higgins, M. E. (1987). Dress and physical attractiveness of women in job interviews. Clothing and Textiles Research Journal, 5, 1-8.

Jones, E. E., \& French, R. S. (1984). Social stigma: The psychology of marked relationships. New York, NY: W.H. Freeman.

Kawakami, K. Phills. C. E., Steele, J. R., \& Dovidio, J. F. (2007). (Close) distance makes the heart grow fonder: Improving implicit racial attitudes and interracial interactions through approach behaviors. Journal of Personality and Social Psychology, 92, 957-971.

Kosut, M. (2006). An ironic fad: The commodification and consumption of tattoos. Journal of Popular Culture, 39(6), 1035-1048.

Koziel, S., Kretshmer, W., \& Pawlowski, B. (2010). Tattoo and piercing as signals of biological quality. Evolution and Human Behavior, 31, 187-192.

Lang, P. J., Bradley, M. M., \& Cuthbert, B. (1995). International Affective Picture System. Gainesville: University of Florida, Center for Research in Psychophysiology.

Langer, E. J., Fiske, S., Taylor, S. E., \& Chanowitz, B. (1976). Stigma, staring, and discomfort: A novel-stimulus hypothesis. Journal of Experimental Social Psychology, 12, 451-463.

Laumann, A. E., \& Derick, A. J. (2006). Tattoos and body piercings in the United States: A national data set. Journal of the American Academy of Dermatology, 55, 413421.

Lombroso, C. (1895). Criminal anthropology. Forum, 20, 33-49.

Lombroso, C. (1896). The savage origins of tattooing. Popular Science Monthly, 4, 793803.

Madera, J. M., \& Hebl, M. R. (2011). Discrimination against facially stigmatized applicants in interviews: An eye-tracking and face-to-face investigation. Journal of Applied Psychology, 97(2), 317-330.

Mann, S. (2005). National poll shows public opinion sharply divided on regulating appearance - from weight to tattoos - in the workplace. Business Wire (30 March 2005). Web (11 March 2008). 
Martin, B. A., \& Dula, C. S. (2010). More than skin deep: Perceptions of, and stigma against, tattoos. College Student Journal, 44, 200-206.

Muraven, M., \& Baumeister, R. F. (2000). Self-regulation and depletion of limited resources: Does self-control resemble a muscle? Psychological Bulletin, 126, 247259.

Murphy, K. R., \& Myors, B. (2004). Statistical power analysis: A simple and general model for traditional and modern hypothesis tests (2nd ed.). Mahwah, NJ: Erlbaum.

Neuberg, S. L., Smith, D. M., Hoffman, J. C., \& Russell, F. J. (1994). When we observe stigmatized and "normal" individuals interacting: Stigma by association. Personality and Social Psychology Bulletin, 20, 196-209.

Neumann, R., Hulsenbeck, K., \& Seibt, B. (2004). Attitudes towards people with AIDS and avoidance behavior: Automatic and reflective bases of behavior. Journal of Experimental Social Psychology, 40, 543-550.

Norvilitis, J. M., Scime, M., \& Lee, J. S. (2002). Courtesy stigma in mothers of children with attention deficit/hyperactivity disorder: A preliminary investigation. Journal of Attention Disorders, 6, 61-68.

Olson, K. R., Dunham, Y., Dweck, C. S., Spelke, E. S., \& Banaji, M. R. (2008). Judgments of the lucky across development and culture. Journal of Personality and Social Psychology, 94, 757-776.

Ostman, M., \& Kjellin, L. (2002). Stigma by association: Psychological factors in relatives of people with mental illness. British Journal of Psychiatry, 181, 494498.

Payne, B. K., Cheng, C. M., Govorun, O., \& Stewart, B. D. (2005). An inkblot for attitudes: Affect Misattribution as Implicit Measurement. Journal of Personality and Social Psychology, 89(3), 277-293.

Pontin, J. (2007, March 25). Artificial intelligence: With help from the humans. The New York Times. Retrieved from http://www.nytimes.com/2007/03/25/business/yourmoney/25Stream.html

Pryor, J. B., Reeder, G. D., Yeadon, C., \& Hesson-McInnis, M. (2004). A dual process model of reactions to perceived stigma. Journal of Personality and Social Psychology, 87, 436-452. 
Pryor, J. B., \& Reeder, G. D. (2011). HIV-Related stigma. In J. C. Hall, B. J. Hall, \& C. J. Cockerell (Eds.), HIV/AIDS in the Post-HAART Era: Manifestations, Treatment, and Epidemiology (pp. 790-806). Shelton, Connecticut: PMPH-USA, Ltd.

Pryor, J. M., Reeder, G. D., \& Monroe, A. E. (2012). The infection of bad company: Stigma-by-Association. Journal of Personality and Social Psychology, 102(2), 224-241.

Quinn, D. M, Chaudoir, S., R. (2009). Living with a concealable stigmatized identity: The impact of anticipated stigma, centrality, salience, and cultural stigma on psychological distress and health. Journal of Personality and Social Psychology, 97(4), 634-651.

Reeder, G. D., \& Pryor, J. B. (2000). Attitudes toward persons with HIV/AIDS: Linking a functional approach with underlying process. In G. Maio and J. Olson (Eds.), Why we evaluate: Functions of attitudes (pp. 295-323). Hillsdale, NJ: Erlbaum.

Resenhoeft, A., Villa, J., \& Wiseman, D. (2008). Tattoos can harm perceptions: A study and suggestions. Journal of American College Health, 56(5), 593-596.

Rinck, M., \& Becker, E. S. (2006). Spider fearful individuals attend to threat, then quickly avoid it: Evidence from eye movements. Journal of Abnormal Psychology, 115, 231-238.

Roberts, D. J. (2012). Secret ink: Tattoo's place in contemporary American culture. The Journal of American Culture, 35(2), 153-165.

Rosner, B. (1983). Percentage points for a generalized ESD many-outlier procedure. Technometrics, 25(2), 165-172.

Rossbach, K. A, Wilson, J. P. (1992). Does a Dog's Presence Make a Person More Likeable? Anthrozoös, 5(1), pp. 40-51.

Stieger, S., Pietschnig, J., Kastner, C.K., Voracek, M., \& Swami, V. (2010). Prevalence and acceptance of tattoos and piercings: A survey of young adults from the southern German-speaking area of central Europe. Perceptual and Motor Skills, $110,3,1065-1064$.

Stirn, A., Andreas, H., \& Brahler, E. (2006). Prevalence of tattooing and body piercing in Germany and perception of health, mental disorders, and sensation seeking among tattooed and body-pierced individuals. Journal of Psychomatic Research, 60, 531534. 
Stuppy, D. J. Armstrong, M. L., \& Casals-Ariet, C. (1998). Attitudes of health care providers and students towards tattooed people. Journal of Advanced Nursing, 27, 1165-1170.

Stutterheim, S. E., Bos, A. E. R., Pryor, J. B., Brands, R., Liebregts, M., \& Schaalma, H. P. (2011). Psychological and social correlates of HIV status disclosure: The significance of stigma visibility. AIDS Education and Prevention, 23(4), 382-392.

Swami, V., \& Furnham, A. (2007). Unattractive, promiscuous, and heavy drinkers: Perceptions of women with tattoos. Body Image, 4, 4, 343-352.

Tiggemann, M. \& Hopkins, L. A. (2011). Tattoos and piercings: Bodily expressions of uniqueness? Body Image, 8, 245-250.

Totten, J. W., Lipscomb, T. J. \& Jones, M. A. (2009). Attitudes toward and stereotypes of persons with body art: Implications for marketing management. Academy of Marketing Studies Journal, 13(2), 77-96.

Towler, A. J., \& Schneider, D. J. (2005). Distinctions among stigmatized groups. Journal of Applied Social Psychology, 35(1), 1-14.

Vanman, E. J., Paul, B. Y., Ito, N. M., \& Miller, N. (1997). The modern face of prejudice and structural features that moderate the effect of cooperation on affect. Journal of Personality and Social Psychology, 73(5), 941-959.

Weiner, B. (1995). Judgments of responsibility: A foundation for a theory of social conduct. New York: Guilford Press.

Wohlrab, S., Fink, B., Kappeler, P. M. \& Brewer, G. (2009). Differences in personality attributions toward tattooed and nontattooed virtual human characters. Journal of Individual Differences, 30(1), 1-5. 


\section{APPENDIX A}

\section{PILOT STUDY}

Goffman (1963) identified three types of stigma: (1) abominations of the body, (2) blemishes of individual character, and (3) tribal stigmas. Tattoos can be classified within each of these categories: (1) they involve a deformation the body, (2) their presence is often regarded as a character blemish, and (3) they can signify a group/tribe membership. Pryor \& Reeder (2011) suggested that one hallmark of stigmas is that they evoke implicit negative attitudes.

In the last few decades, implicit attitude tests, such as the Implicit Association Test (IAT; Greenwald et al, 1998) and the Affect Misattribution Procedure (AMP; Payne et al., 2005), have given researchers a way to quantitatively assess implicit attitudes, and thus, confirm the existence of stigmas. In this pilot study, such a method was used to confirm the existence of a tattoo stigma.

The goal of this pilot study was threefold. First, I wished to verify the existence of a tattoo stigma by assessing participants' implicit attitudes of tattooed and non-tattooed individuals. Second, I wished to explore the relationship between participants' implicit and explicit attitudes regarding tattooed individuals. Third, I wished to identify possible gender differences in the assessments of tattooed males and females. 
I first predicted that participants would judge tattooed individuals as less attractive than non-tattooed individuals at both the implicit and explicit levels. Second, I predicted that implicit and explicit attitudes would be highly correlated. Third, in line with research indicating that tattooed women face a higher degree of discrimination than tattooed men (Hawkes, et al., 2004; Swami \& Furnham, 2007), I predicted that tattooed females would encounter a larger drop in attractiveness ratings than tattooed males.

\section{Method}

\section{Participants}

Seventy-one participants (27 males and 44 females) volunteered to participate in this study. Participants were given extra credit in an undergraduate Psychology class in exchange for their involvement. Data was collected in groups ranging from 15 to 20 participants.

\section{Procedure and Design}

Participants were told that the purpose of the study was to examine the psychological processes at work in the evaluation of abstract art. A brief history of abstract art was given, and participants completed five practice questions indicating their preference for one abstract painting over another.

Participants' implicit attitudes were then assessed using an adaptation of the Affect Misattribution Procedure. Participants were told that their task was to rate the visual pleasantness of a series of abstract paintings. They were told that each painting would be presented for only one second, and therefore, they should make their ratings as quickly as possible. Ratings were made on an answer sheet using the following scale: -3 
$=$ very unpleasant, $-2=$ unpleasant, $-1=$ slightly unpleasant, $+1=$ slightly pleasant, $+2=$ pleasant, and $+3=$ very pleasant.

Participants were also told that, because each painting was to be presented for only a second, a real life signal photo would precede each painting. Fundamentally, the AMP functions so that each "real life" photo serves as a prime that influences the rating of the ambiguous painting that follows. However, in line with Payne's study, participants in the pilot were not made aware of the AMP's true nature; instead, they were told that all real-life images served only as warning signals and to not let them influence their judgments of the abstract paintings. Thus, evaluations of abstract paintings reflected participants' implicit (rather than explicit) attitudes.

Twenty priming photos were presented for one second preceding each abstract painting. Priming photos consisted of five non-tattooed males, five non-tattooed females, five tattooed males, and five tattooed females. All photos were found online, and subjects of priming photos were rated as being of equal relative attractiveness prior to this study. Priming photos were presented at random. Abstract paintings were created online, and mirrored copies of each abstract painting following a tattooed prime alternatively followed a non-tattooed prime as well.

After each (one second) presentation of a prime and (one second) presentation of an abstract painting, a message was presented asking participants to rate the pleasantness of the previous painting on a Likert scale. Likert scale values ranged from -3 (very negative) to +3 (very positive) without the use of a midpoint (0), thus participants' 
responses were forced choice in nature while still allowing participants to express the degree of their feelings.

After a five-minute break, participants explicitly evaluated the attractiveness of the same 20 subjects used in the priming photos. Here, each photo was presented for two seconds, and participants were asked to rate the individuals on a scale from 0 (not at all attractive) to 100 (extremely attractive).

Participants next provided further explicit evaluations by completing a Tattoo Attitude Scale in which they were asked two questions: "Generally, how do you feel about men with tattoos?" and "Generally, how do you feel about women with tattoos?" The Attitude Scale was calibrated from 100 degrees (extremely favorable feelings) to 0 degrees (extremely unfavorable feelings).

Last, participants indicated their age, gender, class, and their own number of tattoos. All participants were then debriefed regarding the true purpose of the study. A number of subjects indicated that they suspected the study involved the evaluation of tattooed individuals; however, no subject picked up on the true nature of the AMP in its ability to evaluate implicit attitudes.

\section{Results}

\section{Implicit Attitudes}

I first examined attractiveness ratings generated during the AMP. For each participant, I computed mean ratings of abstract paintings following tattooed subject and non-tattooed subject conditions, respectively. Comparing these indices, I found that abstract paintings preceded by primes of non-tattooed individuals $(M=.217, S D=.109)$ 
were rated more positively than paintings preceded by primes of tattooed individuals $(M$ $=-.029, S D=.104), F(1,69)=11.7, p=.001, \eta^{2}=.145$. Thus, these ratings showed an overall tattoo stigma main effect (Figure 1).

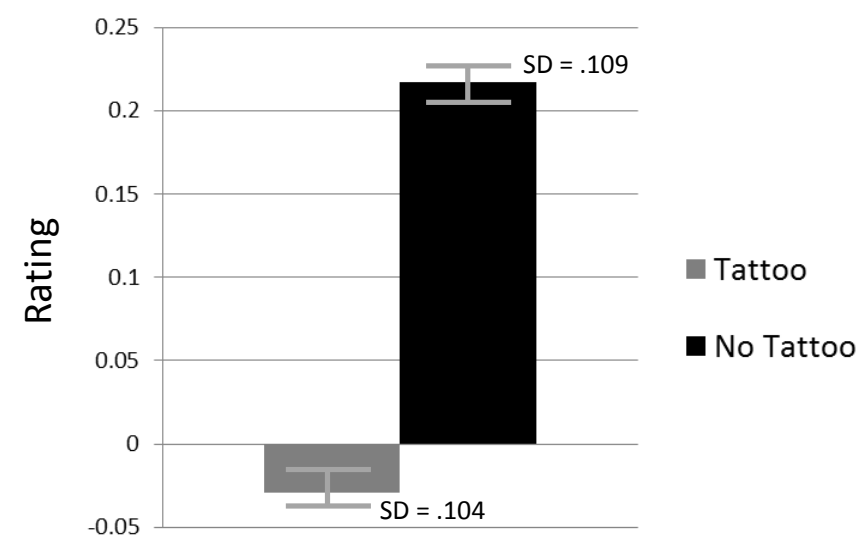

Figure 1. Main Effect of Implicit Attitudes of Tattooed and Non-tattooed Individuals

\section{Explicit Attitudes}

Next, I examined the explicit ratings of the 20 subjects of the photos. For each participant, I computed mean ratings of tattooed individuals and non-tattooed individuals, respectively. Comparing these indices, I found that non-tattooed individuals $(M=66.6$, $S D=1.65)$ were rated more attractive than tattooed individuals $(M=53.8, S D=2.01)$, $F(1,69)=53.0, p<.001, \eta^{2}=.435($ Figure 2$)$. 


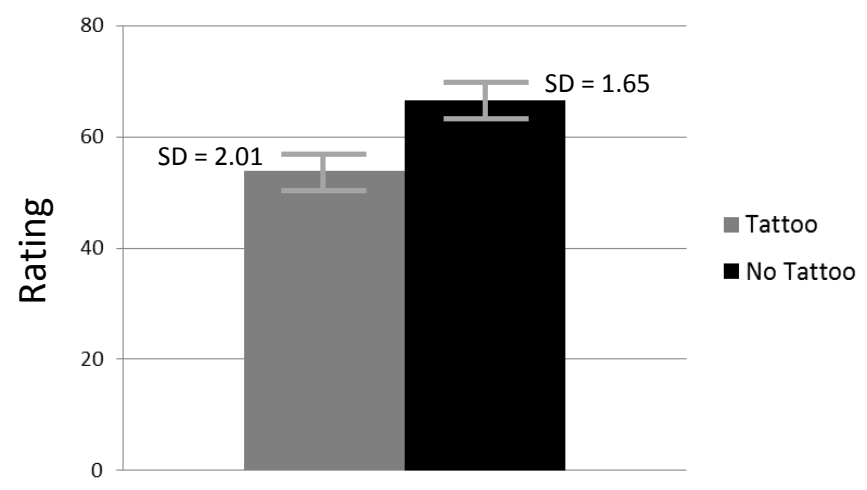

Figure 2. Main Effect of Explicit Attitudes of Tattooed and Non-tattooed Individuals

\section{Additional Findings}

Implicit and explicit attitudes were found to be correlated, $\mathrm{r}(71)=.55, p<.01$ for males and, $\mathrm{r}(71)=.37, p<.01$ for females. A significant interaction was also found to exist between gender of prime subject and tattoo condition for explicit ratings, $F(1,69)$ $=5.72, p=.02, \eta^{2}=.076$, indicating that having tattoos lowered female ratings more than male ratings (Figure 3). This finding supported previous research indicating that tattooed females face a larger degree of discrimination than tattooed males. 


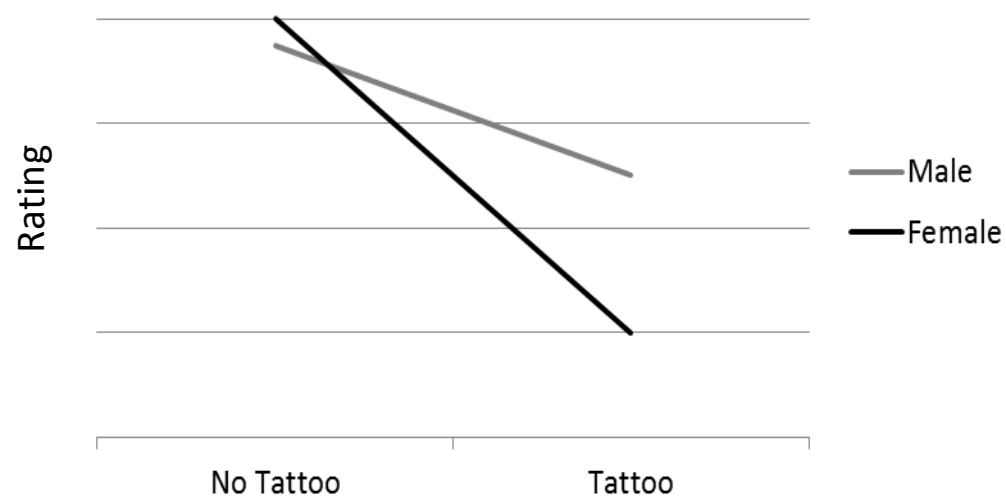

Figure 3. Interaction Effect of Tattoo Condition and Gender of Photo Subject

\section{General Summary of Pilot Study}

In this pilot study, tattooed individuals were rated as less attractive than nontattooed individuals at both the implicit and explicit level. Thus, the existence of a tattoo stigma was supported. This finding validated a further examination of the role tattoo stigma may play in applied setting - particularly, in the highly influential job interview. Madera and Hebl (2011) found that visible stigmas might be distracting and impair memory for information about stigmatized individuals. Thus, the pilot study provided a springboard for studying the role of implicit attitudes regarding tattooed individuals in the job interview setting. 


\section{APPENDIX B \\ MTURK PARTICIPANT RECRUITMENT PAGE}

\section{Social Attitudes Survey}

\section{Instructions:}

* In this HIT you will be asked to answer some questions about some societal attitudes.

* You are required to be a resident of the United States of America and a fluent English speaker in order to participate in this HIT. By a "fluent English speaker," we mean that you studied English in school and that you have a good understanding of basic conversational English.

$*$ You are also required to be at least 18 years of age.

* This not a survey for people who live outside the continental United States.

* You can only complete this survey once. If you do it more than once, you will not be paid for either HIT.

* HITS will be approved or disapproved in a week.

I certify that I am a fluent English speaker residing in the USA and that I am at least 18 years old.

$$
\begin{aligned}
& \text { Yes } \\
& \text { No (please discontinue) }
\end{aligned}
$$

Please go to this link to participate in this study:

https://survey.lilt.ilstu.edu/TakeSurvey.aspx?SurveyID=n62J5o65

If clicking the link does not take you to the study, you can paste it in a browser and then ENTER.

After you have finished the survey, you will be given a completion code number.

Please enter the completion code for your survey here ... 
APPENDIX C

\section{CONDITION PHOTOS USED IN FIRST MINI STUDY}

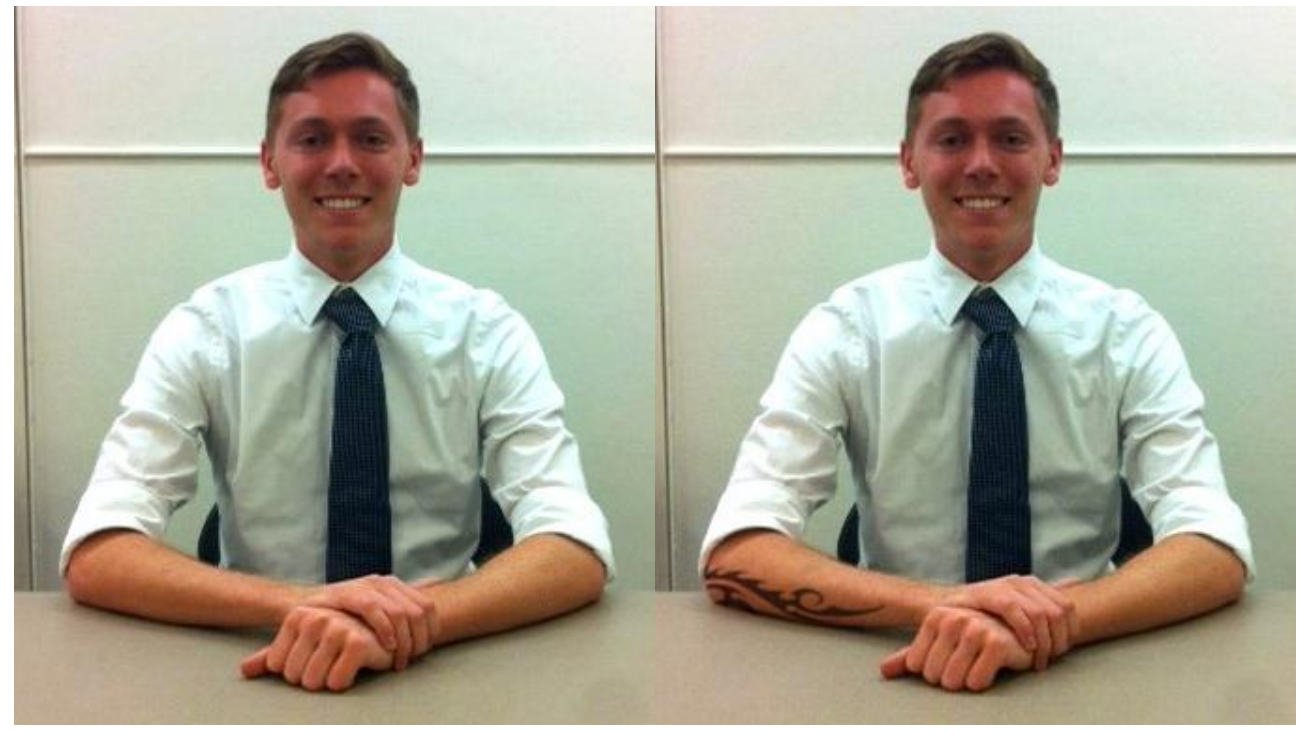

Non-tattooed Male

Tattooed Male

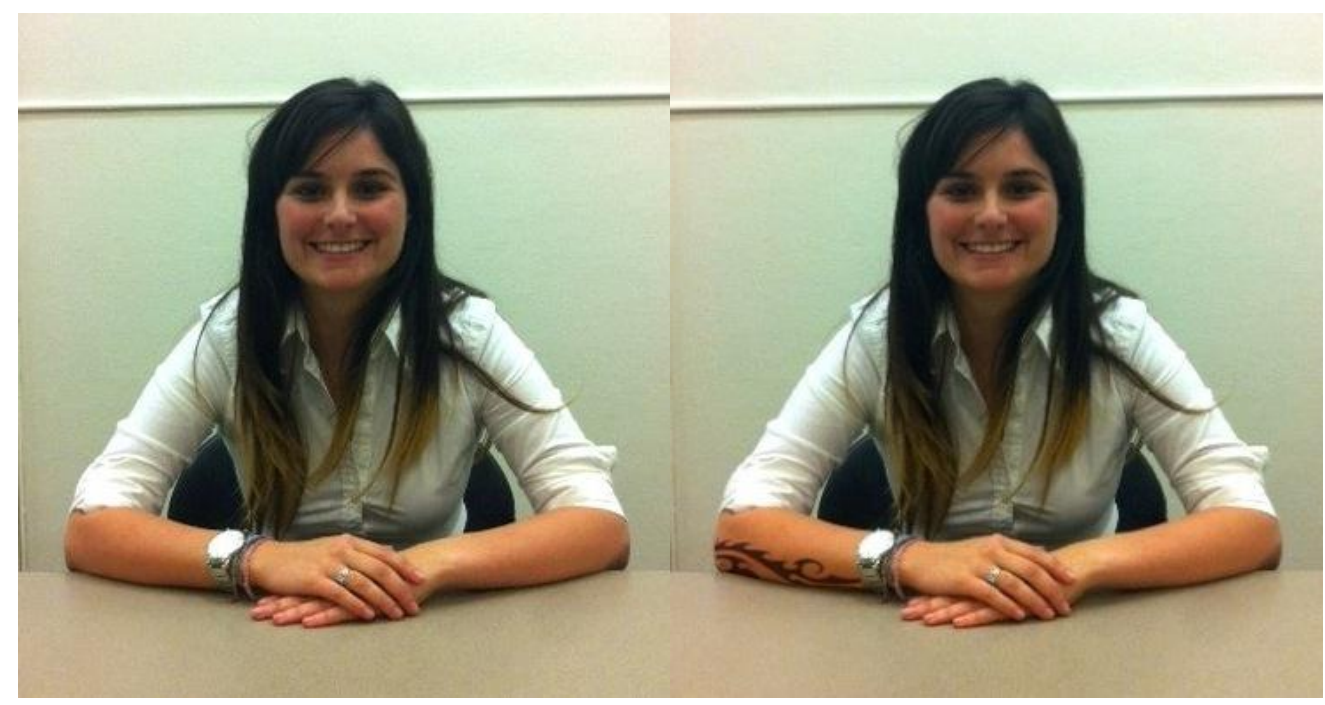

Non-tattooed Female

Tattooed Female 


\section{APPENDIX D \\ SIMULATED INTERVIEW AND INSTRUCTIONS}

You are about to begin the first mini study. In this study, you will see a photo of an actual job candidate and a transcript of his or her interview (name of candidate has been changed). After the interview, you will be asked to recall information about the candidate and give feedback regarding his or her qualifications.

Advance to the next screen when you are ready to view the interview.

Q: Hi Jessie. Welcome to Factor Plus! Please tell me about yourself.

A: Thank you Mr. Lee. I am currently a graduate student at St. Louis University. I plan to graduate in May with a Bachelor's degree in Business, and as of now, my GPA is a 3.6.

Q: Very nice, and congratulations! Are you from the St. Louis area?

A: No, actually, I was born in Massachusetts, but my family moved to St. Louis when I was 12 years old and I've lived there since.

Q: What activities are you involved in at St. Louis University?

A: For the last two years, I've worked as a research assistant to a Doctoral student in Marketing. In this position, I have helped set up a new participant database and have also helped administer a number of surveys.

Q: Very nice. Are you involved in any other activities?

A: Yes, I am a member of Alpha Phi Omega, a service fraternity. As Service Chair, I am responsible for organizing transportation for students from campus to organizations off campus, such as the Humane Society.

Q: Besides your work with the Doctoral student, do you have any other professional experience in Marketing? 
A: Yes, I do; for the last three Summers, I have worked as an office assistant at JP Gibb \& Associates Law Firm. Using Python (the programming language), I helped them design a new website.

Q: Do you know any other programming languages?

A: I am also competent in Java, which has been useful on numerous school projects.

Q: What did these projects entail?

A: In one project, we had to create a game for grade school students that would be both educational and fun. I created a chess game with cartoon figures that helped kids work on their strategy skills.

Q: Jessie, what do you consider to be your greatest strength?

A: When I am working on a project, I tend to work well ahead of schedule. This enables me to work out any problems ahead of time and be confident in my final product.

Q: What is your greatest weakness?

A: To be honest, I had a difficult time with Calculus during college, but with tutoring assistance and extra effort, I persevered and completed 2 levels with a B minus average.

Q: How do you handle stress and pressure?

A: I enjoy being busy, and I usually end up doing my best work when I'm under pressure. Sometimes, if I've been working too long, I will go for a run or do yoga. I'm a big believer in exercise. And sleep!

Q: Describe a difficult work situation or project and how you overcame it.

A: At the law firm I worked at, we once had a key employee suddenly quit. My coworkers and I had to work as a team to pick up the slack. In the end, we managed to share her responsibilities until a new person was hired, and I actually learned a lot from the experience.

Q: So, Jessie, why Factor Plus?

A: I did my research, and Factor Plus continues to be rated as one of the top companies in Marketing today. Also, my cousin's friend has been working for Factor Plus for a few years, and he told that he really likes his job and Factor Plus's positive work environment. 
Q: Why do you want to be an analyst?

A: I want to be an analyst because it seems well-tailored to my competencies in sales and marketing. Additionally, I had the chance to meet the team I would be working with, and they seem absolutely terrific.

Q: Why should we hire you above our other candidates?

A: Because I believe that I am the most prepared person for this job. My coursework in business and my real-world experience in sales and marketing have prepared me well for this position.

Q: What are your goals for the future?

A: Once I gain additional experience, I would like to move on from marketing to a management position at Factor Plus. I hope to be here for many years to come.

Q: Would you be willing to work at any of our offices in the U.S.?

A: Ideally, I would like to remain in the Midwest since this is where most of my friends and family live. However, I would definitely consider taking a position outside the Midwest as well.

Q: Thank you, Jessie. You can expect to hear back from us within the next two months. We still have a lot of candidates that we need to interview.

A: Thank you, Mr. Lee. I really appreciated the opportunity. 


\section{APPENDIX E \\ MEMORY TEST AND INSTRUCTIONS}

You will now answer some questions regarding the content of the interview. You will also be asked to give feedback regarding the candidate's qualifications. It is important that you answer the following questions to the best of your abilities. Please advance to the next screen when you are ready to begin.

1. Where does Jessie attend university?
a) Indiana University
b) Southern Illinois University
c) St. Louis University
d) University of Illinois
e) University of Massachusetts
f) University of Missouri - St. Louis
g) Washington University in St. Louis

2. What is Jessie's major?

Business

Communications

Computer Science

Education

English

Psychology

Marketing

3. What kind of fraternity is Jessie a member of?
A leadership fraternity
A cultural fraternity
A business fraternity
A service fraternity
A pre-law fraternity
An honor's fraternity 
Jessie is not a member of a fraternity

4. What summer job has Jessie held for the last three summers?

Working for a website design company

Working for a grade school organization

Working for the Humane Society

Working as an intern for Factor Plus

Working at a coffee shop

Working for a law firm

Working at a research facility in Massachusetts

5. What programming language(s) does Jessie know?

Python and Java

$\mathrm{C}++$ and Python

$\mathrm{C}++$ and Java

Java only

Python only

C++ only

Python, Java, and C++

6. What is Jessie's self-proclaimed greatest strength?

Working ahead of schedule

Calculus

English

Designing websites

Performing research

Maintaining a positive attitude

Communicating effectively

7. Jesse described overcoming a difficult situation. Where did that situation take place?

In a coffee shop

At a law firm

In a research laboratory

At the Humane Society

At a grade school

In a classroom

At home

8. What did Jessie's difficult situation involve? 
Creating a chess game for grade school students

Finding a scholarship to attend college

Transporting students to the Humane Society

Setting up a participant data base

Finding participants for a research study

Covering the work of an employee who suddenly quit

Preparing witnesses for a difficult trial

9. What are Jessie's work location preferences?

Jessie would like to travel as much as possible

Jessie would prefer to work in the Midwest

Jessie is only willing to work in the Midwest

Jessie would prefer to work in Massachusetts

Jessie is only willing to work in Massachusetts

Jessie has not thought about work location preference

Jessie would like to work abroad

10. When can Jessie expect to hear back from Factor Plus?

The next day

Within a week

Within the next two weeks

Within a month

Within the next two months

Within the next three months

The interview did not specify 


\section{APPENDIX F \\ EFFECTIVENESS EVALUATION ITEMS AND INSTRUCTIONS}

Do you agree or disagree?

1. This applicant has strong qualifications.

Strongly disagree

Disagree

Neither agree nor disagree

Agree

Strongly agree

2. This applicant has impressive experiences.

Strongly disagree

Disagree

Neither agree nor disagree

Agree

Strongly agree

3. I am not impressed by this applicant.

Strongly disagree

Disagree

Neither agree nor disagree

Agree

Strongly agree

4. This applicant is not likely to get the job.

Strongly disagree

Disagree

Neither agree nor disagree

Agree

Strongly agree

5. This applicant did a good job in answering the interview questions.

Strongly disagree 
Disagree

Neither agree nor disagree

Agree

Strongly agree

6. This is an attention check. Please select "Strongly agree."

Strongly disagree

Disagree

Neither agree nor disagree

Agree

Strongly agree

7. The interviewer was probably impressed with the qualifications of this applicant.

Strongly disagree

Disagree

Neither agree nor disagree

Agree

Strongly agree

8. The applicant seemed like a good match for the job.

Strongly disagree

Disagree

Neither agree nor disagree

Agree

Strongly agree

9. I think the applicant would do well in this job.

Strongly disagree

Disagree

Neither agree nor disagree

Agree

Strongly agree

10. The applicant did not seem to be suited for the job.

Strongly disagree

Disagree

Neither agree nor disagree

Agree

Strongly agree

11. The applicant seemed very professional.

Strongly disagree

Disagree

Neither agree nor disagree 
Agree

Strongly agree 


\author{
APPENDIX G \\ AFFECTIVE MISATTRIBUTION PROCEDURE (AMP) EXAMPLE ITEM
}

Painting (example):

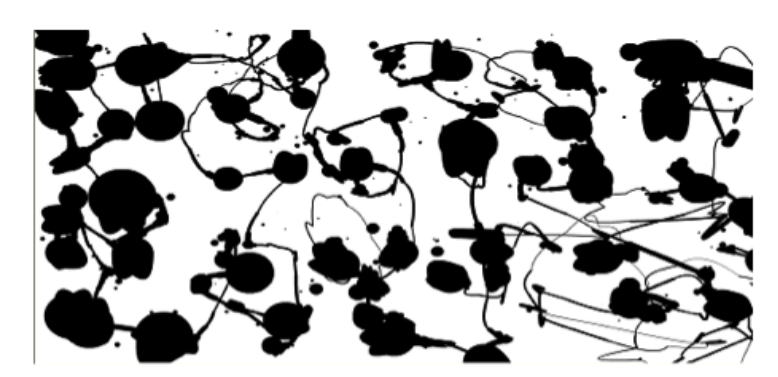

Prompt:

"How pleasant or unpleasant was the previous painting?

\author{
Answer Options: \\ very unpleasant \\ unpleasant \\ slightly unpleasant \\ slightly pleasant \\ pleasant \\ very pleasant
}




\section{APPENDIX H}

\section{EXPLICIT TATTOO ATTITUDE SCALE}

Instructions: The following questions concern people's attitudes towards tattooed individuals. We want to be clear that we are not evaluating you on your responses. We are simply trying to learn about college students' attitudes towards tattoos. All of your responses will be kept completely confidential. Please indicate your response using the scale below.

Directions: The following questions (A-M) require you to use what we call a FEELING THERMOMETER. The Feeling Thermometer is shown below.

\begin{tabular}{|c|c|c|}
\hline \multirow{2}{*}{ POSITIVE } & degrees & \multirow[b]{2}{*}{ Extremely favorable feelings } \\
\hline & 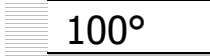 & \\
\hline & $90^{\circ}$ & Very favorable \\
\hline & $80^{\circ}$ & Quite favorable \\
\hline & $70^{\circ}$ & Fairly favorable \\
\hline & $60^{\circ}$ & Slightly favorable \\
\hline & $50^{\circ}$ & Neither favorable nor unfavorable \\
\hline & $40^{\circ}$ & Slightly unfavorable \\
\hline & $30^{\circ}$ & Fairly unfavorable \\
\hline & 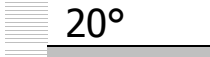 & Quite unfavorable \\
\hline & $10^{\circ}$ & Very unfavorable \\
\hline NEGATIVE & 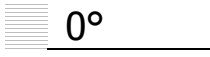 & Extremely unfavorable feelings \\
\hline
\end{tabular}

Using the Feeling Thermometer, please provide a number between 0 and 100 degrees to indicate your feelings about the following groups of people:

\begin{tabular}{|l|l|l|}
\hline A. & Generally, how do you feel about men with tattoos? & \\
\hline B. & Generally, how do you feel about women with tattoos? & \\
\hline C. & More specifically, how do you feel about men with neck tattoos? & \\
\hline D. & More specifically, how do you feel about women with neck tattoos? & \\
\hline E. & More specifically, how do you feel about men with arm tattoos? & \\
\hline F. & More specifically, how do you feel about women with arm tattoos? & \\
\hline G. & More specifically, how do you feel about men with torso tattoos? & \\
\hline H. & More specifically, how do you feel about women with torso tattoos? & \\
\hline
\end{tabular}




\section{APPENDIX I \\ FINAL SURVEY QUESTIONS AND INSTRUCTIONS}

1. In the first mini study, was Jessie (the job applicant) male or female?

Male

Female

2. In the first mini study, did Jessie display any of the following features?

Piercings

Facial scar(s)

Tattoos

Missing teeth

None of the above

3. Generally, how do you feel about men with tattoos?

Extremely favorable feelings

Very favorable

Quite favorable

Fairly favorable

Slightly favorable

Neither favorable nor unfavorable

Slightly unfavorable

Fairly unfavorable

Quite unfavorable

Very unfavorable

Extremely unfavorable feelings

4. Generally, how do you feel about women with tattoos?

Extremely favorable feelings

Very favorable

Quite favorable

Fairly favorable

Slightly favorable

Neither favorable nor unfavorable

Slightly unfavorable

Fairly unfavorable

Quite unfavorable 
Very unfavorable

Extremely unfavorable feelings

5. How many tattoos do you have?

[response options range from 0 to $10+$ ]

6. What is your gender?

Male

Female

No response

7. What is your age?

[response options from 18 to $100+$ ]

8. What is your ethnicity?

African American/Black

Caucasian/White

Asian American/Asian

Indian American

Other, please specify:

9. What is your education level?

Some high school

High school degree

Some college

College degree

Some graduate school

Graduate degree

Ph.D 